\title{
Carolina Freyre de Jaimes, a un siglo de su muerte Una aproximación biográfica (1844-1916)
}

Carolina Freyre de Jaimes, a century after his death A biographical approach (1844-1916)

\section{María del Carmen Escala Araníbar ${ }^{1}$}

Pontificia Universidad Católica del Perú

"No tenemos más trabajo intelectual que el periodismo" Carolina Freyre de Jaimes La Patria, 13 de marzo de 1880

\section{Resumen}

Una reciente investigación sobre la escritora Carolina Freyre de Jaimes y su manejo discursivo de la arenga bélica ha mostrado su papel durante la guerra del Perú contra Chile. Esta aproximación biográfica, reconstruida con información verificada en fuentes primarias y en la crítica divulgada, permite comprender la participación de Carolina Freyre en el escenario cultural y en la política nacional. Se plantea que las influencias de su esposo Julio Lucas Jaimes la favorecieron y ella pudo mostrar su talento y ser reconocida como escritora.

1 Actualmente es predocente de la especialidad de Historia en dicha universidad. Sus investigaciones se orientan a la presencia femenina en el espacio socio cultural en Lima de fines del siglo XIX y principios del XX. Correo electrónico: mescala@pucp.edu.pe 
Palabras claves: Carolina Freyre, Escritoras peruanas, Perú, Siglo XIX, La Patria (periódico)

\section{Abstract}

A recent investigation about the writer Carolina Freyre de Jaimes and her discursive handling of the harangue of war has shown her role during the Peruvian war against Chile. This biographical approach, reconstructed with verified information in primary sources and in critical works, allows to understand the participation of Carolina Freyre in the cultural scene and in the national politics. It is argued that the influences of her husband Julio Lucas Jaimes favored her and enabled her to show her talent and be recognized as a writer.

Keywords: Carolina Freyre, Peruvian writers, Peru, XIX century, La Patria (newspaper)

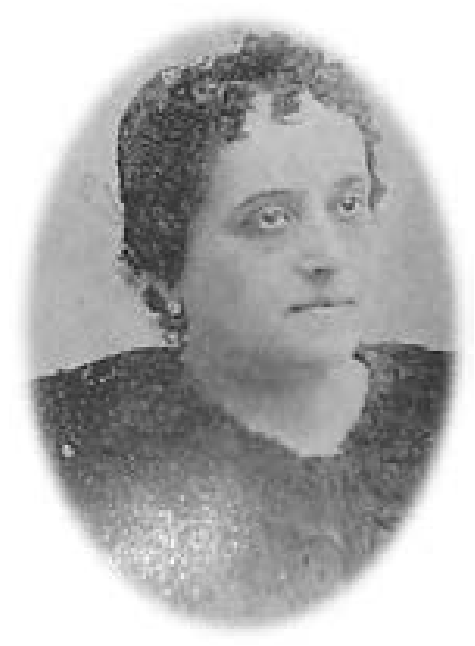

Imagen 1. Carolina Freyre de Jaimes 1844-1916

(Valda de Jaimes Freire 1972: 15) 
Un reciente estudio sobre la tacneña Carolina Freyre de Jaimes y su discurso patriótico, difundido meses previos a la ocupación de Lima (Escala 2015)², dejó al descubierto una desconocida faceta de la mujer peruana en la guerra contra Chile, de lideresa arengando a un contingente constituido principalmente por mujeres, ancianos y niños acantonado en la capital ante la inminente ocupación de Lima por las tropas chilenas. En ese episodio bélico, la escritora, desde su columna la "Revista de Lima" en el diario La Patria, de manera sostenida, proclamó una retórica nacionalista y patriótica en su esfuerzo por canalizar las emociones públicas, como miedos y aflicciones, hacia actividades patriótico-solidarias con los connacionales. Simultáneamente, alimentó deseos de venganza, asegurando a sus lectoras y lectores que el ejército nacional, pese a su menguada fuerza, era suficientemente poderoso para enfrentar la superioridad del enemigo.

La arenga bélica en el discurso femenino peruano no tuvo precedente antes de Carolina Freyre de Jaimes y llama la atención, porque esta estrategia enunciativa de predominio masculino permite mostrar la participación de la mujer durante la guerra en una tarea distinta de las conocidas. Por esta singularidad, a partir de la historia, es importante reconstruir una aproximación biográfica de la escritora dado que, si bien existe información sobre ella, esta es escasa y lamentable-

2 Este artículo es parte de la tesis de licenciatura El ángel del hogar y el ángel de la guerra (1844-1880) de la autora. El tema se centra en la arenga bélica desde la perspectiva femenina y en las publicaciones que Carolina Freyre de Jaimes difundió a través de su columna "Revista de Lima" en el diario La Patria entre enero y setiembre de 1880. 
mente parte de ella cae en imprecisiones. Esta semblanza, se reconstruye con datos que han sido verificados en fuentes primarias, incluido el archivo arzobispal, y la crítica divulgada. Respecto a la prolífica obra de la escritora, será referida para enunciar su trayectoria literaria ya que ese aspecto excede el propósito de este artículo.

Carolina Freyre de Jaimes ${ }^{3}$ fue una mujer de avanzada en su época. Por su talento, se distinguió como una reconocida escritora. Desde muy joven escribió para diversas publicaciones como educadora, especialmente de sus jóvenes lectoras. Con el conocimiento y la experiencia adquirida en la imprenta familiar, se embarcó en proyectos periodísticos importantes que la registrarían como pionera en la dirección femenina tanto en el Perú como en Bolivia. Su convicción patriótica se reafirmó cuando desplegó sus estrategias discursivas de manera sostenida en un diario con el objetivo de levantar un frente de resistencia ante la inminente ocupación de Lima por las tropas chilenas.

Si partimos del hecho de que en la segunda mitad del siglo XIX, conforme con la tradición colonial, era difícil para una mujer, a pesar de su talento, tener influencia y poder para alcanzar sus propósitos puesto que dislocaría lo convencionalmente establecido, ¿cómo Carolina Freyre de Jaimes se

192 consolidó en el espacio cultural y participó en la escena política? En este artículo se sostiene que la escritora recibió el respaldo de su esposo, el escritor y político boliviano Julio Lucas Jaimes, quien habría actuado como hilo conductor en

3 Se ha optado por la escritura del apellido paterno de la escritora como Freyre, tal como lo hicieron su padre y hermanos respecto a Freire o Freyres, también consignados, pero en menos oportunidades. 
la maraña de poder político limeño atendiendo confrontaciones entre anticivilistas y propierolistas cuyas influencias alcanzó favorablemente a Carolina Freyre, quien logró consolidarse en el medio cultural y político limeño.

La exposición se desarrolla de manera cronológica en tres etapas. Se parte del año de su nacimiento en 1844 hasta 1880, meses previos a la ocupación de Lima y de allí se sigue su huella hasta el año de su muerte en 1916. El itinerario comienza en su natal Tacna; allí, durante su niñez y juventud, Carolina se inclinó por las bellas letras y descubrió el amor en el político y escritor boliviano Julio Lucas Jaimes. El segundo tiempo se ubica en la capital, donde mieles y hieles les fueron servidas al matrimonio Jaimes-Freyre por sus pasiones compartidas: la literatura y la política. En el tercer tiempo, seguimos su rastro algunas veces tenue, en otros, denso. Tacna, Lima, Bolivia y Argentina fueron recorridos a lo largo de su vida; Buenos Aires fue su destino final.

\section{Tacna. "Si la hubierais visto hace algunos años" (1844-1870)}

El patriotismo de Tacna, tierra que vio nacer a Carolina Freyre Arias, fue puesto a prueba en varios momentos de su historia. Significó la puerta de entrada de la emancipación americana al Perú iniciada en Buenos Aires, hecho que significó que el 18 de enero de 1823 se le reconociera al pueblo como villa (Quirós y Nieto 1831: t. I, 315) y que cinco años después,

4 El 26 de mayo de 1880 Tacna cayó ante los chilenos. El progreso que prometía la ciudad se truncó; el estado de postración trajo a la memoria de la escritora recuerdos de su tierra en su temprana juventud. 
el 26 de mayo de 1828, se elevase como Heroica Cindad por su desempeño en la Independencia, según reza el dispositivo legal firmado por el presidente José de la Mar (Quirós y Nieto 1832: t. III, 84-85). Desde allí, la marcha de la ciudad hacia la modernidad fue imparable con medios de comunicación, lugares de esparcimiento y sociabilidad, lo último en tecnología y movimiento comercial. Más adelante, la puesta en marcha del ferrocarril consolidó el movimiento mercantil que beneficiaría también a Bolivia (Ley del 11 de julio de 1876) ${ }^{5}$.

Los antecedentes de la historia y el vínculo geográfico de Tacna con Bolivia tienen su razón de ser en este estudio. Con el desenvolvimiento de Tacna y la interrelación con los bolivianos en exilio se llegó a tejer una red de afinidades con conocidos, amigos y parientes que involucró a la escritora Carolina Freyre.

\subsection{La precocidad ilustrada}

Carolina Freyre Arias nació el 4 de enero de 1844 en Tacna. Fue la segunda hija del matrimonio de don Andrés Freyre Fernández y doña Juana Arias; tuvo cinco hermanos: el mayor, Andrés, participó en las campañas de Tarapacá y de La Breña en la guerra contra Chile; Clorinda, la tercera, difundió su producción literaria en El Ramillete a través de la imprenta de su padre $^{6}$; le siguen a ellos Ricardo y Eloísa (Gambetta 2001: 32).

5 Congreso de la República. Reglamento Especial del Ferrocarril de Arica y Tacna. Consulta: 5 de marzo de 2016. En: <http://www.leyes.congreso.gob.pe/Documentos/LeyesXIX/1876049.pdf>

6 Conversaciones personales con la sobrina nieta de Carolina Freyre, Magda Benavides-Freyre Cafferata entre 2009-2010. Ella es hija de la poetisa tacneña Carmen Cafferata de Benavides-Freyre. El contacto se estableció a través del Club Departamental de Tacna en Lima. 
El último fue Roberto, el tenaz periodista del periodo de la ocupación chilena de Tacna (Basadre 2009: 56-62)7.

Evidentemente, las letras mecieron las cunas de los FreyreArias y también la información, las publicaciones y otras formas de comunicación fueron parte de sus vidas, especialmente para Carolina. Se desconoce si con holgura o sacrificio, lo cierto es que sus padres dispusieron de la educación de la niña con esmero ${ }^{8}$, permitiéndole desarrollar su creatividad, inteligencia y afición por la lectura. No se descarta que preceptores privados le enseñasen a recitar la prosa y el verso con los gestos precisos de este arte y a distanciarse del lenguaje cotidiano.

Según señala el bibliófilo chileno José Domingo Cortés?, quien registró el primer recuento biográfico de la escritora Carolina Freyre, con apenas tres años, fue colocada en el centro del patio del colegio Educandas en Tacna con un gran libro para que leyese un romance. Cortés afirma que al terminar, el público presente quedó sorprendido por la habilidad de la niña, no solo expresiva sino también lectora; por la revelación, el representante de educación en la ciudad prometió a la directora que la niña recibiría una beca de estu-

7 Basadre sostiene que Roberto Freyre tomó la dirección de El Tacora y allí mantuvo encendido el espíritu patriótico en Tacna ocupada, por lo que fue atacado constantemente por las turbas chilenas a la voz: "No queremos más panfletos, ni más Freyres ni Barretos".

8 Años más tarde, Carolina reflexionaba sobre la educación femenina, que dependía de la capacidad adquisitiva de la familia. "La clase proletaria, las hijas de los pobres, que representan el mayor número, tienen que contentarse con el mezquino aprendizaje que ofrecen las escuelas gratuitas". Véase "Una necesidad imperiosa". El Correo del Perú; 2 de marzo de 1872.

9 Parnaso Peruano, 1871 
dios, suscribiéndolo con "Jamás ninguna con más derecho". Cortés continua exaltando los dones de la escritora cuando hace referencia al desempeño de la adolescente en el mismo colegio atendiendo "[...] el cargo de profesora de la clase de aritmética".

Sin duda, el talento y habilidad que mostró la escritora en su edad adulta hacen referencia a la maduración progresiva de sus habilidades, que la ubicó a la vanguardia respecto de sus pares. No obstante, algunas de las afirmaciones de Cortés, tras la confrontación de fuentes, carecerían de validez y precisión.

En primer lugar, considerando la fecha de nacimiento, la niña no tuvo tres, sino cuatro años y diez meses, y a esa edad Carolina no pudo ser alumna de las Educandas, como sabemos, el Estatuto Provisional para el Bienestar del Pueblo (1820) señaló la obligatoriedad de los padres o apoderados de enviar a la escuela a los niños varones mayores de cinco años (González 1970: 14-15), aunque no menciona la edad que debían hacerlo las niñas; de hecho, no fue menor de cinco años de edad, dado que el género masculino marcaba la pauta. En 1840, la educación femenina aún era deficiente (Basadre 1983, t II: 310). Se debe recordar que Pardo, en su Reglamento General de Instrucción Pública, indicó que la edad

196 obligatoria para que los niños asistan a la escuela era los seis años la edad "para ambos sexos" (1876: 9). En segundo lugar, si bien las autoridades de educación entregaron becas escolares, estas se asignaban a los niños de precaria condición económica. Ser hija del administrador y dueño de una de las principales imprentas de Tacna y probablemente con preceptores privados, no suponía una niña pobre a los ojos de la comunidad. Finalmente, Carolina Freyre, en 1856, con 
doce años de edad, no habría podido ejercer en Educandas el "[...] el cargo de profesora de aritmética". La afirmación de Cortés desdice el ordenamiento educativo de la época. Desde la Novísima Recopilación de las Leyes de España (1846) el celo en el nombramiento de preceptores competentes persistió en la República.

De acuerdo con lo expuesto, es improbable que en 1848 Carolina haya asistido al colegio como alumna y que a los doce años fuese maestra. Sin embargo, esto no excluye que una invitación le permitiese participar en el evento escolar por sus habilidades. Se presume que, próxima a cumplir cinco años de edad, la niña habría aprendido a leer, incluso desarrollar su capacidad memorística que le habría facilitado expresar y declamar armoniosamente los romances con los gestos que este arte exige; y con doce años, ubicarse a la vanguardia de sus pares, es improbable como maestra, pero es posible como asistente.

El interés de Cortés por exaltar las habilidades de la escritora respondería al reconocimiento que iba ganando entre los escritores, poetas y público lector en Lima. Esta situación le sería económicamente significativa a la publicación de su Parnaso Peruano. Así lo señalan algunos de sus contemporáneos cuando afirman que el chileno se interesaba más por las ventas producidas que por el contenido de sus publicaciones. Según Feliú "Cortés atendía menos [e]l valor de las poesías que al sonante en efectivo de la suscripción para su obra" (1993: v. II, 63-64). Su percepción coincide con "M.A.G." 10 , en su opinión el Parnaso Peruano era una obra limitada y sobre el chileno ma-

10 Las iniciales corresponden al escritor Manuel Adolfo García (Varillas 1992: 87). 
nifestó “[...] ¡cuán fácilmente se gana fama en el Perú cualquier advenedizo, y cuán caro se hace pagar lo mismo que él le dá!” (El Correo del Perú, 14 de diciembre de 1872).

Severos cuestionamientos que mostrarían una práctica frecuente del bibliófilo chileno, conocida y criticada por muchos como el comentario que hizo "Orestes" desde México años más tarde. En su artículo publicado en La Revista Universal y que recoge El Correo del Perú, "Orestes" elogió el compendio de Cortés Poetisas americanas (1875), pero lamentando el desacierto en la selección de las producciones. A su juicio, ha dado "[...] espacio en demasía para unas, breve e injusto para otras", refiriéndose, sutilmente al privilegio brindado a la escritora Gertrudis Gómez de Avellaneda. Al respecto "Orestes" sugiere:

Quejárase, por ejemplo, con derecho bonísimo la señora Carolina Freyre de Jaimes, muy elegante escritora en prosa y á las veces inspirada y no común poetisa, hay de ella en el libro de Cortés una mediana poesía religiosa, de inspiración difícil y vaga, de forzada entonación, que no da por cierto idea de la hábil y seductora manera con que maneja la escritora peruana el habla riquísima española (12 de marzo de 1876$)^{11}$.

Ciertamente, colocar en primer lugar la obra de la popular escritora cubana, en comparación con el espacio que de-

11 La escritora cubana Gertrudis Gómez de Avellaneda ocupa, en la obra, diecinueve páginas; es seguida por la chilena Mercedes Marín y la mexicana Esther Tapia de Castell con catorce y doce páginas, respectivamente. Carolina Freyre se encuentra entre las menos favorecidas con solo cuatro. Llama la atención que, si bien el índice ordenado alfabéticamente empieza con "Acevedo (Josefa)", la producción de las escritoras la encabeza "Gómez de Avellaneda, Gertrudis". 
dicó a la poetisa peruana, aseguraba al chileno suculentas ganancias por las ventas de su libro. Además, el énfasis del mexicano puesto en el desliz "involuntario" de Cortés revela no solo la resonancia de la producción literaria de Carolina Freyre, sino también su fama por esos lares.

\subsection{Experiencia tipográfica. La Imprenta Libre y los Freyre-Arias}

Para la historia del periodismo tacneño, Andrés Freyre Fernández es un referente obligado. En 1844, año en el que nació Carolina, don Andrés trabajaba como administrador de la Imprenta del Gobierno; en 1851 fundó la Imprenta Libre ofreciendo a la comunidad tacneña publicaciones de tinte político y de cultura. En 1855, editó La bella tacneña; entre 1858 y 1859 entregó a Iquique su primer periódico El Mercurio de Tarapacá. De regreso a Tacna, en 1867, fundó el semanario El Independiente (González 1965-1966: 89) con la dirección de Ramón Rojas y Cañas, que se constituyó en la voz del liberalismo tacneño (Porras 1970: 39). La imprenta de don Andrés Freyre continuó con otros periódicos, el 1 de enero de 1856 salió El Correo de Tacna y el 24 de mayo, El Comercio. En noviembre de 1866 apareció, de la tipografía La Abeja, de Carlos García, La Revista del Sur, dirigida y administrada por don Andrés Freyre (Gambetta 2001: 29); en este medio de divulgación, los desterrados bolivianos manifestaron su rechazo contra el gobierno de su presidente, Mariano Melgarejo.

En alguna de estas publicaciones y en otras de breve aparición, la joven Carolina comenzó a difundir sus creaciones como en La bella tacneña (González 1952: 53). A los catorce años compuso una comedia para el colegio y junto a otros 
jóvenes ${ }^{12}$ editó la revista Alborada en homenaje al Perú por su aniversario (González 1965-1966: 90) probablemente en la imprenta de los Freyre; más adelante, con Modesto Molina y otros coetáneos fundaron la Cofradía Lírica (Salas 2009-2010: 130).

La vena periodística de don Andrés inspiraría a Carolina cuando inició su propia aventura con El Álbum en Lima y en Sucre. Es evidente el dinamismo, inteligencia y también belleza de la joven Carolina. Doña Magda, sobrina nieta de la escritora, recuerda que en las conversaciones familiares, sus mayores evocaban la elección de Carolina en un concurso de belleza. Sus recuerdos se confirman con el grabado del evento que se difundió en las cajitas de fósforo "Sinfonía Azul", una de ellas rescatada por María Luisa, esposa de su hijo Raúl (Valda de Jaimes Freire 1972: 17).

Carolina Freyre desde joven forjó su carácter para alcanzar sus aspiraciones y difundir su producción fue una de ellas. Su movilización en el espacio público, limitado para las mujeres, significó mayor esfuerzo. Es indudable que sus virtudes literarias le entreabrieron las puertas del espacio público y el respaldo de las buenas relaciones de su esposo, el boliviano Julio Lucas Jaimes, la ayudó a abrirlas y asentarse tras de ellas.

\subsection{Los Jaimes-Freyre: confluencia de la política y las bellas letras}

Conocido con el apelativo de "don Javier de la Brocha Gorda” (Tauro 1993: 50), el escritor Julio Lucas Jaimes nació en

12 Esos jóvenes eran Mario Centore, Federico Barreto y Enrique Hurtado y Arias. 
1840 en Potosí, Bolivia (González 1952: 53) y llegó a Tacna en 1864, como muchos de sus connacionales exiliados del gobierno de Melgarejo. Con veinticuatro años de edad ya registraba un ardoroso quehacer político e intelectual. A pesar de su oposición al dictador boliviano Melgarejo, desde 1868, Jaimes ejerció la representación diplomática de Bolivia como cónsul a petición de sus connacionales residentes en Tacna (Jaimes 1964: 8). En este escenario, Carolina y Julio se conocieron y más adelante se unieron en matrimonio, probablemente en el año $1865^{13}$. Con la alianza nupcial, las redes políticas y literarias se ampliaron y con ello también la movilidad literaria de la escritora.

Respecto a la descendencia del matrimonio, se ha sostenido que tuvo seis hijos. Sin embargo, la investigación que se inició en el archivo arzobispal de Lima proporcionó información que da cuenta de un vástago más sumando la descendencia a siete hijos. El mayor se llamó Julio, como su padre; le sigue el poeta Ricardo que nació en Tacna el 12 de mayo de $1868^{14}$, atestiguaron en su partida los bolivianos exiliados en esa ciudad Mariano Baptista y Melchor Mariano Ricardo Terrazas. La tercera fue Carolina, como su madre, falleció pocos años después de casada, su matrimonio fue apadrinado por Rubén Darío, amigo de Ricardo; le sigue Julia Rosa; a continuación Federico Nicolás, seguido de Carlos Alberto; finalmente

13 Elsa Paredes en su Diccionario biográfico de la mujer boliviana (1965: 120-121) afirma, sin mencionar su fuente, que el matrimonio Jaimes-Freyre se realizó en 1863. Sin embargo, me atrevo a deducir que fue en 1865; tomo como referencia la fecha de nacimiento de Ricardo, su segundo hijo, 12 de mayo de 1868; contado regresivamente, es razonable tres años a cinco para suponer el año del matrimonio.

14 Considerado precursor de la corriente modernista latinoamericana. 
Raúl, el último de los Jaimes-Freyre, también escritor, poeta y diplomático, nació en Potosí en 1888 (Gambetta 1988: 10-12). Es preciso, para la construcción de este recuento de vida, detenerse en los niños limeños, Federico Nicolás y Carlos Alberto, el primero por los vínculos espiritual y político que extendieron sus padres con personalidades políticas que acompañaron parte de sus vidas; y el segundo, para dar cuenta de su existencia, hasta la fecha desconocida.

Nicolás de Piérola apadrinó al niño Federico Nicolás ${ }^{15}$ el día lunes 22 de diciembre de 1879, probablemente durante la noche. Ese día es crucial en la historia nacional, pues la fuerte actividad política suscitada días atrás por el inesperado

15 En el Archivo Arzobispal de Lima se encuentra la solicitud para sentar la partida de bautismo del niño Federico Nicolás Jaimes Freyres [sic]; la presentó la madrina del niño, Natividad Moreyra viuda de Frisancho (Archivo Arzobispal de Lima; Legajo 10, Expediente 10, año 1882). El documento con fecha 7 de febrero de 1882 señala que Carolina Freyre se encontraba con sus hijos en Tacna. La solicitud para registrar el bautizo del pequeño Nicolás deja constancia que, por haber sido oficiada en Casa de Gobierno y no en una parroquia, la inscripción en el libro respectivo se postergó y la gestión se aletargó por los vaivenes de la guerra contra Chile. No obstante, la señora Natividad argumenta que "[...p] or una distracción involuntaria de los padres del niño, no fue sentada la respectiva partida en los libros de la Parroquia de San Marcelo a la que pertenecía por el domicilio de los interesados". La afirmación sería imprecisa. Se sabe, por información de la escritora en su "Revista de Lima", que los Jaimes Freyre residían en Chorrillos, difícilmente le correspondería esa parroquia; su mención es probable por la cercanía a la Casa de Gobierno. Por otra parte, en la solicitud se indica que el niño nació el 12 de agosto de 1872 y el bautizo se realizó el 22 de diciembre de 1879, es decir que, en el momento del bautizo Federico Nicolás contaba con siete años de edad, este dato es interesante y sorprende, porque era inusual posponer el bautizo por tanto tiempo, por la creencia de que si un niño fallecía "morito", su alma permanecería eternamente en el purgatorio. 
viaje de Mariano Ignacio Prado, presidente del Perú, terminó con la asunción de Piérola como jefe supremo al día siguiente. El acto bautismal del pequeño se llevó a cabo en la capilla de la casa del supremo gobierno, fue solemnizada por quien sería obispo de Arequipa, Ambrocio Huertas. Amadrinó la señora Natividad Moreyra viuda de Frisancho y atestiguaron los señores Francisco Pasos y Dionisio Derteano ${ }^{16}$. Los lazos de amistad que los Jaimes-Freyre tenían establecidos con estos personajes se fortalecieron con el vínculo bautismal. nEl penúltimo hijo de los Jaimes Freyre, Carlos Alberto ${ }^{17}$ recibió el sacramento, tres meses después que Federico Nicolás, el 31 de marzo de 1880 en la parroquia Corazón de Jesús. Con apenas nueve meses y siete días de nacido, se deduce que el niño nació el 22 o 23 de junio de 1879.

El matrimonio Jaimes-Freyre partió de Tacna a Lima, probablemente en 1870; se conjeturan dos motivos. El primero, se refiere a la seguridad física y salubridad pública que no garantizaba Tacna después del terremoto y tsunami que afectó las costas del sur el 13 de agosto de 1868 que cobró numerosas vidas humanas y cuantiosos daños materiales (Cope-

16 Francisco Pasos con Ricardo Palma editaron El Liberal y fundó El Nacional. Dionisio Derteano, empresario y político vinculado a los negocios agrícolas y las finanzas, con otros banqueros y empresarios en Lima donaron un millón de soles para enfrentar la guerra contra Chile. Derteano concurrió a la batalla de Miraflores con el grado de coronel. En su casa se dio la Junta de Notables (Tauro 2001: t. 12: 1991; t.6, 831-832).

17 En la búsqueda de información de Federico Nicolás, se encontró información de Carlos Alberto. La ficha de inscripción consigna lo siguiente: “[...] Juan de Albinagoita bautizó a un niño de sexo masculino, de 9 meses y 7 días, raza blanca, hijo lejítimo [sic] de Julio Lucas Jaimes, natural de Bolivia, residente en Lima y doña Carolina Freyres [sic] natural de Tacna [...] (Archivo Arzobispal de Lima; LH (B) Libro 23; folio 275). 
llo 1870: 191-198). A ello se sumó, cinco meses más tarde, la epidemia de fiebre amarilla que llegó por la costa desde Panamá y se llevó a la cuarta parte de la población tacneña (Sors 1868: 14).

Si bien la enfermedad se controló con las medidas sanitarias que el gobierno implementó ${ }^{18}$, la amenaza de rebrotes se mantuvo latente por lo que se justificaba salir de Tacna. El otro motivo responde al anhelado ascenso profesional de los Jaimes-Freyre y Lima, "la tierra prometida" los esperaba. Así, antes de la caída del dictador boliviano Melgarejo, Julio Lucas Jaimes renunció al cargo consular en Tacna y con Carolina e hijos trasladaron a la ciudad capital sus saberes y memoria.

\section{Lima. "Mi débil pluma puesta al servicio durante diez años" (1871-1880) ${ }^{19}$}

El beneficio de la explotación del guano que gozó la generación de la bohemia de Palma no se iguala con el que alcanzó la siguiente generación. Pese a la carestía, disfrutó de la prosperidad reflejada en las lujosas manifestaciones de la élite e ideales modernizadores del país. Años previos a la guerra con Chile, el Perú vivió cierta estabilidad política respecto

18 El gobierno del presidente Balta a través de un paquete de medidas decretadas el 21 y 22 de agosto de 1868 ordenó al Ministro de Beneficencia brindar auxilio y entregar recursos necesarios a los pobladores y pueblos afectados por "el terremoto, incendios e inundaciones". Congreso de la República. Archivo digital. Consulta: 25 de agosto de 2016. En: <http:/ / www.leyes.congreso.gob.pe/LeyNoNumeP.aspx>

19 Una década en Lima. Lo recuerda la escritora cuando Tacna cayó ante las tropas chilenas. En La Patria. Lima, 28 de agosto de 1880. 
a las décadas anteriores. "Tanto como consecuencia de su antigua tradición de señorío cuanto por el relativo desarrollo que acreditaba en el primer siglo de vida independiente, la Ciudad de los Reyes era la única que podía ofrecer entre nosotros un 'ambiente' literario realmente significativo" (Varillas 1992: 260). Salvando distancias, la literatura, la vida social y la bohemia también tuvieron su momento; el florecimiento de la literatura femenina (Basadre 1983: t. V, 457) dio lugar a la primera generación de ilustradas (Denegri 1996). “[ [.. m] uchas de ellas fueron poetisas, no habiendo podido salvarse de la epidemia rimada que se metió en la prensa como derivación incontrolable del romanticismo bullicioso y tenaz" (Miro Quesada 1957: 124).

Efectivamente, la incursión femenina en el oficio de escribir no fue bien vista en la sociedad del momento; no obstante, ganaron su espacio gradualmente y con distintas estrategias discursivas publicitaron sus obras. Unas subordinaron y moderaron sus textos a la crítica; otras, protegieron su identidad con un seudónimo o el anonimato; otras más se abrieron camino en la prensa extranjera (Batticuore 2005: 116-125); no faltó quienes propiciaron influencias entre amigos y conocidos en la élite. La lectoría de las autoras femeninas se fue ampliando evidenciando la disminución del analfabetismo. La modernidad liberó a muchas mujeres de sus habituales actividades y pudieron dedicar más tiempo a la lectura y escritura. Esta circunstancia explicaría el incremento de publicaciones dirigidas a la familia y a la mujer, incluso en diarios eminentemente políticos como La Patria con su columna "Revista de Lima" de la escritora Carolina Freyre de Jaimes.

En Lima, la escritora tacneña suscribió ensayos, poesía, dramas históricos, discursos sobre temas políticos, sociales 
y románticos, posiblemente hasta marchas patrióticas. El Club Literario de Lima, en 1874, la incorporó a su exclusivo grupo; fue la única mujer entre los treinta y dos miembros (Salas 2009-2010: 130); al año siguiente le otorgó la medalla destinada "[...] al mejor trabajo leído [...]" por su estudio sobre Flora Tristán (Chamorro, mayo 21 de 1977).

A los pocos años de su llegada a Lima, su carrera se veía prometedora. Entre los años 1876 y 1877 escribió la trilogía de narrativa ficcional: Pizarro, Blanca de Silva y María de Vellido [sic], cada uno enmarcado en la Conquista, Colonia e Independencia, respectivamente. En lo que sigue, se describe brevemente estas producciones que nos acerca a la expectativa que generaba en la población este tipo de eventos en la escena cultural de la época.

Con Pizarro inauguró esta secuencia; si bien no fue publicada, el comentario que hizo Eugenio Larraburre unos días después de escenificarse la obra permite conocer el argumento. La escritora concierta un triángulo amoroso en el que introduce la sublevación de Quisquis. Según la apreciación de Larraburre, Carolina confiere poder a Nusta para preparar en secreto la venganza que deberá cobrar a los conquistadores españoles por las muertes ocasionadas; pero el amor que surge entre Pizarro y la bella Nusta, la obnubila y la aleja

206 de su propósito. No obstante, el indio Yanapaccoc, también enamorado de ella, no pierde la esperanza de arrojar al intruso español y reconquistar el amor de la joven. Su venganza arremete con furia contra Gonzalo, hermano del conquistador, y lo mata. En ese mismo momento, Pizarro y Nusta se casaban, pero la felicidad del español se empaña cuando se entera de que su hermano había sido asesinado por Yanapaccoc, el rebelde de Quisquis. Pizarro hace capturar al 
indio y pese a las súplicas de Nusta, decide matar a su rival y enemigo (Larrabure 1934-1936: vol. 2, 207-302).

El 17 de febrero de 1876, la obra se escenificó por la compañía de teatro del actor Leopoldo Burón, que llegó a Lima para cumplir una serie de presentaciones en el teatro Principal de Lima (Basadre 1983: t. V, 504). La producción contó con el acompañamiento musical y las composiciones de Claudio Rebagliati.

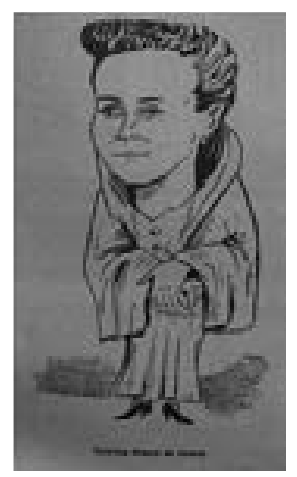

Imagen 2. Caricatura de Carolina Freyre de Jaimes

(El Comercio, 21 de mayo de 1977)

En 1977, luego de cien años de la representación teatral, Guillermo Chamorro en un artículo publicado en El Comercio dio cuenta de la magnificencia de la obra. Según sus fuentes, la obra fue tan aclamada por el público que la compañía realizó dos presentaciones más de las programadas, una al día siguiente, 18; la otra, el 22 de febrero en homenaje a la autora. La noche fue engalanada con la presencia del presidente Mariano Ignacio Prado; el coronel Andrés Avelino Cáceres se sumó al evento enviando la banda militar para amenizar la presentación en los entreactos. Al terminar "[...] cayó sobre el patio del teatro una lluvia de poemas, entre 
éstos seis décimas altamente elogiosas, que don Ricardo Palma compuso en honor a doña Carolina y que, al concluir el drama, el actor español recitó en medio de aplausos", según manifiesta Chamorro.

Esa noche fue muy especial también para la ciudad. El público residente en Chorrillos por la temporada de verano que llegó a la ciudad especialmente para disfrutar la presentación fue atendido por la empresa de trenes que ofreciendo su servicio expreso de retorno a mitad de precio. Al día siguiente, los periódicos recordaban a sus lectores la gran noche. Para Eugenio Larrabure y Unanue “[...] el drama 'Pizarro' es, sin disputa, el mejor de los cuatro que sobre este personaje se han escrito en diversos países de América" (Chamorro 1977).

Los triunfos continuaron para la escritora. En el año anterior, 1876, el presidente Mariano Ignacio Prado había convocado a un concurso literario como parte de las celebraciones patrias. Carolina Freyre se presentó al certamen con el drama sobre la época de la Independencia María de Vellido [sic] que mereció el premio al segundo lugar. Dos días después del homenaje que recibió Carolina por Pizarro, el 24 de febrero, Burón escenificó María de Vellido. El éxito siguió acompañando a la escritora.

Nuevamente, en el marco de las celebraciones patrias de 1879, el gobierno promovió su habitual concurso literario; esta vez, la escritora presentó una trama desarrollada en la Colonia del siglo XVIII. Blanca de Silva fue premiada el 10 de julio y meses después se estrenó en el Teatro Principal (Basadre 1983: t. V, 504). Afortunadamente, estas dos últimas obras llegaron a nuestros días. María de Vellido salió en 1878 
de la imprenta ligada a su padre La Revista del Sur, en tanto que Blanca de Silva se editó en la imprenta El Nacional de La Paz en 1883.

Además de ser asidua espectadora teatral, la escritora preparó obras dramáticas que fueron estrenadas en los principales teatros de Lima y Tacna. Si para las mujeres ilustradas de su generación escribir ya era una actividad restringida, introducirse en la dramaturgia significó irrumpir en otro campo masculino y exponerse a la severa crítica de la opinión pública alineada a la mentalidad de la época.

Las primeras publicaciones de Carolina que se publicaron en Lima fueron las que hizo desde Tacna como colaboradora en El Nacional entre 1867 y 1869. Se hizo conocida en Lima con los poemas "Fugacidad" y la vívida composición Arica en la que refleja el drama y dolor de la población como consecuencia del terremoto y tsunami que sufrió la región sur del país en agosto de 1868; la "Carta a mi amiga Leonor Manrique" podría ser su seudónimo con el que firmaría la novela Deudas del alma en 1868 (Castañeda y Toguchi 2000: v. 2, 41-50). Con la crítica a Una estrella más en el horizonte develó su talento reflexivo y valorativo sobre los cambios literarios. No se han encontrado trabajos de la autora fechados en 1870, cuyo silencio pudo deberse al traslado de la residencia familiar a Lima.

Luego de instalarse, Carolina y su esposo Julio Lucas se desempeñaron como escritores y sus nombres coincidieron en algunas publicaciones. A la par que Carolina trabajó para El Correo del Perú, Julio Lucas lo hizo en La Patria como redactor principal. Unos meses más tarde Carolina se integró al medio con su "Revista de Lima" permaneciendo hasta el 11 
de setiembre de 1880. Mientras que eso sucedía, Carolina reanudó sus aportes a El Nacional desde el 6 de mayo de 1871 con el poema "Recuerdo". Empezó a escribir para El Correo del Perú en 1871; el artículo "Al bello sexo" fue su carta de presentación en Lima (Herrera, 2012). En su última contribución en esta publicación, el 30 de diciembre de 1871, invitó a sus lectores que le envíen sus propias producciones a La Bella Limeña que iniciaría sus actividades al año siguiente. Esperaba que los suscriptores de El Correo del Perú se convirtieran en colaboradores directos de la nueva publicación. Al parecer, era una práctica frecuente que todo novel escritor colaborase en distintas revistas de ese tiempo (Varillas 1992: 236) y a ello apeló. La escritora colaboró con El Correo del Perú hasta el año 1876 con varios títulos, entre ellos: "Un tipo", "Una gran misión", "Espíritu del siglo", "Una necesidad imperiosa", "El teatro", "El hogar", "Flora Tristán", "Muerta para el mundo", "Los triunfos del corazón", y la poesía "Al declinar el sol" (Herrera, 2012). Algunos de estos títulos se reprodujeron igualmente en otras revistas.

La mención de El Correo del Perú permite reflexionar sobre el carácter misógino de algunos lectores y miembros del gre$m i 0^{20}$ que en esa época permanecían renuentes a aceptar el avance femenino en las letras y compartir con ellas la profesión. Escudándose en el anonimato insultaron y minimiza-

210 ron su labor intelectual. Carolina no escapó a esta situación, una muestra se encuentra en la sección "Crítica Literaria" de este diario (Lima, 14 de diciembre de 1872) con "Las revistas de La Patria”, su autor, con el seudónimo M.A.G. se

20 Carta de Carolina Freyre a Juana Manuela Gorriti; con "gremio" Carolina Freyre identificaba al conjunto de escritores de Lima (Gorriti 1892: 55-56). 
refirió a la escritora y a su columna sabatina con frases displicentes por su trabajo e intromisión en un espacio que no le correspondía por ser mujer. Si bien aceptó que Carolina poseía "[...] habilidad, instrucción en un grado superior al de las personas de su sexo entre nosotros, y que como poetisa cuenta [con] pocas rivales en el Perú" ella, dice, se toma la libertad de adjudicarse el derecho de "[...] apreciar su pluma más de lo que vale, se ha coronado con las de la vanidad, y demuestra una suficiencia que sería vituperable hasta en una escritora de sobresaliente mérito”. En opinión de M.A.G., la inteligencia de Carolina solo puede ser superior entre su género; sin embargo, esta superioridad, por proceder de una mujer resulta una vanidad que debe censurarse.

El carácter misógino de M.A.G. se confirma cuando sostiene que la escritora "[...] se apropia de un aspecto viril que no le cuadra, se presenta arrogante y vestida con el peto esgrimiendo la espada de las amazonas". Para muchos de sus congéneres, una mujer carece de talento y si lo tiene la acerca al hombre; de allí que Carolina "se apropia de un aspecto viril...". Lamentablemente, esta minimización también viene con ingenuidad como la expresada por Modesto, un lector de la publicación que envió una carta titulada "Carolina Freyre" para defender a la escritora de M.A.G. con los siguientes argumentos:

¿Por qué se supone que Carolina Freyre ha tomado un aspecto viril que no le cuadra, se le hiere en lo más vivo, en su amor propio? [...] no comprendemos por qué las Ciencias y Literatura deban de ser tarea propia de varones, de tal suerte que cuando una muger se mezcla en ella, haya de decirse que toma un aspecto viril.

$¿ \mathrm{O}$ hemos de ser nosotros los varones, como los hermanos mayores mal criados que se complacen en destruir los 
juguetes de nuestras hermanitas menores? No, y mil veces no. Por lo que á nosotros toca, detestamos semejante papel, y confesamos que tenemos a mucha honra cuidar de que las coronas de nuestras hermanas, sean de cristal ó de otra sustancia, estén siempre brillantes (28 de diciembre de 1872).

El discurso de Modesto resulta revelador; en su defensa descubre el predominio, la jerarquización y los prejuicios respecto a los intentos femeninos de hacerse un lugar en el espacio público. En la tarea autoimpuesta, Modesto sugiere justificar las tareas femeninas por ser obra de mujeres, cualquier error que se detectase debe perdonársele porque es parte del rol viril. Al asumirse ellos como mayores, declara las actividades de ellas como menores, simples juegos e inocuos juguetes que pretenden copiar a sus modelos, los varones. Si son aceptados y halagados es porque "comprensiblemente" bien o mal son hechos por mujeres. El insulto - ya sea soterrado, descarado o ingenuo-, la minimización y la disculpa a la labor intelectual femenina fueron persistentes. No obstante, las situaciones adversas hacen más fuertes a las personas.

En 1872, el nombre de la escritora se registró en dos números de la breve aparición de La Bella Limeña con "Un amor desgraciado". El romanticismo se destaca con la oposición del padre a una relación de enamorados, por la presión de su acreedor quien también pretendía a la joven. La muerte

212 del amor elegido y su reclusión en el convento contraponen altos valores con ínfimos sentimientos humanos. Las lecciones moralizantes mantuvieron en vilo la expectativa de las lectoras y lectores. En la emblemática Revista de Lima ${ }^{21}$ para

21 Su primera aparición data del 1 de octubre de 1859 hasta 1863. Fue el medio de expresión de la generación literaria romántica de Palma, Sala- 
la historia republicana, Carolina Freyre presentó, en 1873, dos composiciones de índole personal "A mi hija Carolina" y "Constancia". La composición "Quien da pronto, da dos veces" propicia la reflexión sobre la moral y virtud a través de personajes, a quienes envuelve en una lección de caridad; dos ensayos se agregan al conjunto "El hogar" y "El baile". En cuanto a las adaptaciones históricas, "Andrea Bellido" es un episodio de amor romántico durante las guerras por la independencia; y "Ccora Campillana" presenta al conquistador europeo Francisco Pizarro encandilado por la belleza nativa de la princesa Cantillana [sic], quien se debate entre aceptar el amor del conquistador o conservar su rol de guardiana de la tradición inca y de la honra de Guainacaba y de sus tesoros. En "La hija del cacique"22, la escritora se basa en la historia de la conquista del Brasil por los portugueses para narrar una historia de amor, poder y transculturación.

Por otra parte, a su dedicada creación intelectual se agregan las colaboraciones que envió al exterior. Desde Argentina, los directores de La Ondina del Plata. Revista semanal de literatura y modas (1875-1879), Luis Telmo Pintos y Pedro Bourel, invitaron a Carolina Freyre para publicitar sus composiciones (Sosa 2003: 13-21). Otro país que vio su trabajo fue México, tal como pone en conocimiento Orestes en su artículo publicado en La Revista Universal y que recoge El Correo del

verry, Cisneros y otros. La Revista de Lima reapareció en 1873 y en ese año participó Carolina Freyre de Jaimes.

22 En el pie de página, la escritora indica que su trabajo se basa en Apuntes sobre el Brasil en sus primitivos tiempos de D. Antonio de Minhos y Souza de 1730. La historia de Paraguazú fue difundida en la obra de José Bernardo Suárez Rasgos biográficos de mujeres célebres de América en 1872. En la carátula se indica que el autor fue visitador de escuelas y el texto fue utilizado en colegios para niñas. 
Perú (Lima, 12 de marzo de 1876). En suma, a pesar de sus críticos, la producción literaria de la escritora peruana fue reconocida dentro y fuera del país.

Es preciso señalar que en esta década la escritora publicó en dos medios periodísticos, que resultan fuentes importantes para indagar sobre la vida cotidiana limeña: El Álbum y $L a$ Patria. La primera es precursora de las publicaciones dirigidas por mujeres en el Perú y en Bolivia. La segunda, de cuya imprenta salió El Álbum, fue su casa periodística que la acogió con su columna "Revista de Lima" durante la etapa que residió en Lima.

\subsection{El Álbum. Revista semanal para el bello sexo ${ }^{23}$}

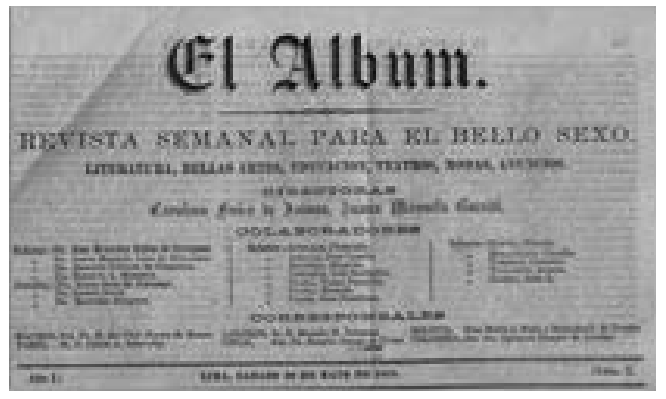

Imagen 3. El Álbum

La palabra "álbum" nos recuerda la carpeta o libro en cuyas hojas se conservaban poemas, letrillas de canciones, dedicatorias, retratos, recortes de diarios, dibujos, flores secas,

23 Publicación difundida entre mayo de 1874 y enero de 1875. Fue fundada por Carolina Freyre de Jaimes y Juana Manuela Gorriti. La imagen de la publicación ha sido tomada del blog de Omar Rocha "Letra Siete". "El Álbum”. Consulta: 17 de enero de 2017. http://letrasietebolivia.blogspot.pe/2014/07/cafetin-con-gramofono.html 
cintas y otros objetos siempre dispuestos a ofrecer recuerdos no siempre nostálgicos. Una práctica social común, avanzado el siglo XIX, fue circular el propio álbum entre los familiares y amistades no solo para el intercambio de dedicatorias, sino también con el objetivo de exponer los talentos para el deleite de sanas vanidades. En los diarios de la época, se pueden encontrar declaraciones de admiración entre una y otra persona. Una muestra de ello se ve en la Aurora Literaria de Sucre, donde aparecieron algunos textos que intercambiaron la boliviana María Josefa Mujía ${ }^{24}$ y Carolina Freyre en el primer lustro de los sesenta (Rocha 2014); ambas, unidas por lazos de amistad, saludaron sus talentos con composiciones que se correspondieron.

\section{A la distinguida poetisa señorita María Josefa Mujía}

Desde aquí escuché tu acento

Tierna inspirada cantora,

I tu voz encantadora

conmovió mi corazón,

I tu lenguaje sublime

Tu espresivo sentimiento

Despertó en mi pensamiento

Una grata admiración

$[\ldots]$

\section{A la Sta. Carolina Freire} de Jaimes

De tu lira dulce i fina, Carolina,

Los acentos escuché

I su grata melodía

Su armonía

Con entusiasmo admiré

$[\ldots]$

Las escritoras Carolina Freyre de Jaimes y Juana Manuela Gorriti $^{25}$ se embarcaron en su propia publicación y decidie-

24 María Josefa Mujía, poetisa boliviana, perdió la vista a los catorce años de edad.

25 Nació en 1818 en Salta, Argentina. Se casó muy joven con el militar boliviano Belzú; en los círculos sociales se hablaba de "la conducta poco 
ron llamarla El Álbum precisamente para llevar esta práctica social a un ámbito mayor e inclusivo. Pretendieron hacer de la publicación una plataforma en la que incipientes escritores pudiesen exponer sus creaciones literarias, dedicar composiciones personales y colaborar con temas de interés para la comunidad nacional. Preciso es señalar que antes de que El Álbum salga a la venta, las revistas para el público femenino eran dirigidas y escritas por hombres apoyados con colaboraciones de escritoras.

El 23 de mayo de 1874, desde la imprenta de La Patria, Freyre y Gorriti pusieron en circulación El Álbum. Revista semanal para el bello sexo. Con el clásico protocolo inaugural se anunció su presencia en los principales medios de prensa. El 19 de mayo El Comercio comentó que el proyecto se venía preparando desde hacía algún tiempo. En el mismo día, El Nacional, de manera festiva, auguró que el propósito de convertir la revista en tribuna para la producción literaria sería una revolución, dada la popularidad de ambas directoras. Al día siguiente La Opinión Nacional lo veía como señal de progreso en la capital e instrumento para educar a la mujer; por su parte, La Patria, el mismo día de la divulgación expresó:

decorosa de los cónyuges, Belzú que tenía muchísimas amantes, y la esposa poco seria y muy amiga del entonces presidente Ballivián”. Por sus pretensiones políticas de hacerse de la presidencia de su país, Belzú fue expatriado al Perú. Gorriti llegó a Lima acompañándolo junto con sus dos hijas. Belzú regresó a Bolivia y Juana Manuela se quedó en Lima. Para su manutención escribía en distintas publicaciones; abrió una escuela primaria, un colegio para señoritas e inició sus Veladas literarias concurridas por distintos artistas. Fundó con Carolina Freyre El Álbum, después con Numa Pompilio Llona La Alborada. Gorriti en Lima tuvo dos hijos Julio Sandoval y Clorinda Puch. Regresó a Buenos Aires y continuó escribiendo (Berg 1997: 131-146). 
Reservándonos juzgarlo con el interés y respeto que merece siempre lo que es producción del espíritu y fruto de la delicada imaginación de la mujer, limitándonos por hoy a participar, que en la tarde de este día aparecerá el número 1 del Álbum [sic], periódico ya anunciado, cuya dirección corre a cargo de las tan bien conocidas escritoras, señoras $\mathrm{D}^{a}$ Carolina Freyre de Jaimes, y D ${ }^{a}$ Juana M. Gorriti. Sabemos que en atención al mérito de quienes lo dirigen y a su objeto, se le tiene preparada una brillante acogida (23 de mayo de 1874).

Tenían corresponsales en las principales ciudades de Latinoamérica y España. En Madrid, María del Pilar Sinués de Marco; en París, Carlos A. Salaverry; en Londres, Ricardo M. Terrazas; en Chile, Rosario Orrego de Uribe; en Bolivia, María J. Mujía y Mercedes B. de Dorado; y en Colombia, Agripina Samper de Ancízar. Con algunos inconvenientes técnicos en los primeros números, su aparición satisfizo la expectativa de sus lectores. El Álbum fue elogiado por su contenido temático y por la progresiva y mayor presencia de trabajos femeninos. Sus secciones se dedicaron a la literatura, bellas artes, educación, teatro, modas y un espacio reservado para anuncios económicos. La mayoría de las colaboraciones fueron suscritas por la tacneña, desde breves cuentos, poesía, ensayos, episodios históricos y su infaltable columna "Revista de Lima" que trasladó de La Patria (Salas 2009-2010: 162). Esto da cuenta de la presencia de la escritora en los treinta y cuatro números de la publicación.

Desde el primer número hasta el décimo quinto (23 de mayo-29 de agosto 1874), la revista estuvo codirigida por Carolina Freyre y Juana Manuela Gorriti. A partir de la siguiente publicación, el nombre de Gorriti desapareció de El Álbum para inscribirse en su propio proyecto: La Alborada (1874-1875). Gorriti rompió su vínculo con una breve nota publicada en La Patria: "La que suscribe se retira desde hoy 
de la dirección de este periódico" (2 y 4 de setiembre de 1874). En tanto, Carolina Freyre asumió la dirección.

Con tres publicaciones de la misma línea: El Correo del Perú, El Álbum y La Alborada dirigida a un mismo público y con la crisis económica que la población atravesaba, se dificultaba el pago de los suscriptores y con ello la permanencia de El Álbum en el medio se debilitaba (Salas 2010: 149). Pese a las contrariedades, Freyre continuó publicando hasta que una nota en La Patria informó que: "Su directora nos ha pedido que anunciemos la suspensión temporal, hasta que pueda realizarse el arreglo de su parte económica poco satisfactoria en las actuales circunstancias de pobreza del país. Nos constan los sacrificios que cuesta el sostenimiento de esa publicación" (29 de enero de 1875). El Álbum llegó hasta el trigésimo cuarto número.

Es innegable que factores exógenos incidieron en el cierre de la publicación; no obstante, se desconoce el motivo que obligó a Gorriti a abandonar El Álbum, ¿diferencia generacional?, ¿discrepancia política?, ¿injerencia de terceros? En lo que sigue, procuraremos acercarnos a los hechos, meses antes y meses después de la renuncia de Gorriti.

\subsection{Freyre y Gorriti. Sociedad, conflicto y rompimiento}

218 Avanzando un poco más allá del primer lustro de la década, las dos escritoras fueron las más representativas en el ámbito limeño, desarrollaron una amistad aunada por las letras y consolidada con un proyecto común: El Álbum. Los motivos de la ruptura de Freyre y Gorriti podrían ser diversos, desde desigualdad de responsabilidades, relaciones más influyentes, celos profesionales, desconfianza, secretos develados, en fin. La brecha generacional entre ambas escritoras era amplia, veinti- 
séis años las separaban ${ }^{26}$; a pesar de ello, vivieron situaciones similares que pudieron hacerlas compatibles, por ejemplo, el vínculo que tuvieron con Bolivia. Carolina era peruana y estuvo casada con Jaimes, político y escritor boliviano al igual que algunos de sus hijos. Juana Manuela era argentina y contrajo matrimonio con el militar boliviano Manuel Isidoro Belzú, más tarde presidente de ese país, sus hijas fueron bolivianas. Ambas perdieron hijos adolescentes; Carolina, a Federico Nicolás; y Juana Manuela, a Clorinda; las dos residieron en Sucre, Bolivia, en distintos periodos. Pese a estas conexiones, ¿qué motivos repercutieron en las excelentes relaciones amicales para que se convirtieran en beligerantes y hostiles?

El desafecto encubierto implicó la ausencia de Carolina Freyre a las veladas que Gorriti organizaba en su casa entre 1876-1877. La renuncia abrupta de Gorriti a la codirección de El Álbum no fue en buenos términos y podría tener su correlato en el apasionamiento periodístico de Jaimes, esposo de Carolina, cuando este adoptó el estilo de la Tradición de Palma para insistir en el tozudo chisme boliviano de cuestiones de alcoba entre Gorriti, Ballivián y Belzú (Glave 1995) ${ }^{27}$

26 Carolina nació en 1844 y Juana Manuela en 1818. Cuando fundaron El Álbum, Carolina contaba con treinta y Juana Manuela cincuenta y seis años de edad. Carolina aportó además de su talento, la experiencia familiar tipográfica, la administración de una imprenta, así como la dirección; por su parte, Juana Manuela también incorporó talento, experiencia y relaciones personales. Podría pensarse que debido a que El Álbum se editaba en la imprenta La Patria y considerando además, el peso de las relaciones que los Jaimes tuvieron con los directores y dueños de esta publicación Carolina; no se descarta que Carolina pudo tener mayor jerarquía en la asociación que no sería bien vista por Juana Manuela.

27 Glave señala que en Bolivia la historia es parte del discurso cotidiano que se ha hecho casi oficial. Según Glave, fue la base "[...] de uno de los 
inmiscuyéndose en el "comadreo" boliviano. Esta situación evidenciaría un Jaimes impulsivo, alentado por la vehemencia propia del "redactor de pelea" o gacetillero especie de "mil oficios" como describe Porras a quienes se dedicaban a esta actividad ${ }^{28}$.

Su entusiasmo hace presumir que la publicación satírica $L a$ Mascarada. Fandango semanal, político económico, crítico, burlesco y de trueno (Basadre 1983: t. V, 198-200) de La Patria, bajo la redacción principal de Jaimes, enemistó a las damas cuando el 8 de agosto de 1874 una caricatura en la página central satirizó a los personajes de la política limeña de turno vestidos a la usanza romana. Con el título "El último día de César" se insinuaba la muerte del presidente Manuel Pardo representado por Julio César; como mal presagio, Pardo, al salir de Palacio fue herido por el capitán Juan Boza. La desdichada coincidencia orientó las investigaciones hacia los autores de la publicación:

argumentos de la novela teatral Guano maldito. En el Manual de Historia de Bolivia de Humberto Vásquez Machicado, el periodo presidencial correspondiente a Manuel Isidoro Belzú incluye el drama de amores y celos que ensangrentó casi diez años la historia de Bolivia”. Y Tulio Halperín Donghi en Reforma y disolución de los imperios ibéricos 1750-1850 “[...] asume que el enfrentamiento entre Ballivián y Belzú, 'encontró estímulo en la incontrolable pasión del presidente por la esposa de Belzú”'. El Perú no escapó a esta tendencia. Parte de la historiografía nacional a la mención de Juana Manuela Gorriti hace referencia a sus veladas y a la supuesta relación extramatrimonial, quizás para destacar un acto de virilidad en esta mujer. Así también lo refiere Basadre (1983: t. V, 456).

28 " "...] la crónica local, en la que entonces se involucraban todos los aspectos de la vida diaria, debía ser al mismo tiempo reportero policial, crítico teatral, literario y taurino, cronista social y comentarista político; y cargar, encima de todo esto, una competente dosis de buen humor para hacer reír a los lectores a base de cualquier suceso inexplotable" (Porras 1970: 38-39). 
Julio Lucas Jaimes y Benito Neto (El Comercio 31 de agosto de 1874) ${ }^{29}$. La cercanía de la fecha del atentado con la decisión de Gorriti de abandonar El Álbum anunciado con la nota el 2 de setiembre hace suponer cierta simpatía hacia Pardo o al grupo político que se sumaría a otras situaciones conflictivas que Gorriti no estaría dispuesta a dejar pasar.

Por otra parte, las simpatías políticas de una y otra facción habrían entrado en conflicto cuando Carolina buscó la solidaridad de las lectoras, a través de El Álbum, mostrando a su esposo como víctima de un supuesto complot político maquinado por el gobierno de Pardo. Esta situación no le habría caído bien a Juana Manuela. Para Carolina,

Los disturbios de la política, la borrasca que cunde hoy entre los círculos sociales, acaba de tocar directamente a la humilde autora de esta revista. Uno de los redactores de "La Patria", mi esposo al fin, acaba de ser envuelto en esas tenebrosas maquinaciones que se llaman odios políticos y que arrastran en su torbellino que arrebatan la libertad hasta a los seres más leales, hasta a las conciencias más nobles y puras. Si hay entre vosotras mis queridas lectoras, una esposa y una madre, que su corazón me haga justicia y que el elocuente idioma del sentimiento exprese lo que oculta el alma, lo que calla la pluma en este momento (1874: 29 de agosto).

Otra de las ligerezas de Jaimes, que tocó a Carolina, habría involucrado al poeta ecuatoriano Numa Pompilio Llona ${ }^{30}$. Así lo hace saber la tacneña en la epístola que dirige a Gorriti declinando la invitación a sus tertulias:

29 El Comercio informó: “[...] han sido reducidos a prisión D. Julio L. Jaimes y D. Benito Neto, a quienes se les ha puesto a disposición del juez del crimen”.

30 Fue colaborador de El Álbum, pero se desligó para trabajar con Gorriti en La Alborada. 
Ayer muy tarde recibí la amable invitación de $\mathrm{Vd}$., pero debo confesar francamente que aun cuando la hubiera recibido á tiempo, siempre me habría sido imposible corresponder á ella. / Si otra persona que no fuera $\mathrm{Vd}$, es decir una mujer distinguida y de talento, una amiga á quien siempre he guardado el culto del cariño y de la estimación más sincera, me hubiera convidado á sus reuniones literarias, me habría contentado con darle las gracias y decir "no puedo" á Vd., le debo algo mas y se lo ofrezco, le debo una explicación. /

Supongo que á sus tertulias literarias mitad por deber, mitad por necesidad, se ha visto $\mathrm{Vd}$. precisada á convidar á todos los del GREMIO [sic] y que entre esos todos se encontrará la persona, para mí antipática con razón, del señor Llona; Vd. comprende que yo y todo lo que se relaciona con Jaimes no cabe es materialmente imposible que quepa donde está Llona, son nombres y personas esencialmente refractarias! / He aquí mi única razón, mi querida Da. Juana Manuela, -supongo que la encontrará Vd. justa y que se dignará $\mathrm{Vd}$. disculpar mi ausencia de las reuniones antes [sic] las demás señoras (Gorriti 1892: 55-56).

La carta que Carolina extendió a Gorriti, fechada el 20 de julio de 1876, revela el esmero por enmascarar las fricciones ya existentes entre ambas; Gorriti cursó la invitación a Carolina Freyre y no a su esposo, a quien correspondía, según las formalidades hacia una mujer casada. Además, si se considera que el ciclo de las veladas de Gorriti se inauguró el 16 de julio (Batticuore 1990: 25) y la invitación que cursó fue el 19 del mismo mes, tres días después, es obvio que tuvo una doble intención. Carolina Freyre denota la descortesía: "Ayer muy tarde recibí la amable invitación de Vd". A pesar del sugerido desacierto de la anfitriona, Carolina pareciera decir que no le afecta cuando sostiene que "[...] aun cuando la hubiera recibido á tiempo, siempre me habría sido imposible corresponder á ella". Queda claro que ambas se limitaron a cumplir con el formalismo. Al parecer, por 
afinidad conyugal Carolina tomó distancia de Gorriti, probablemente de todo evento y personas desafectas a los Jaimes-Freyre, como enfatiza cuando se refiere al "GREMIO".

Lamentablemente, el proyecto periodístico de estas dos mujeres que lejos de buscar el lucro pensaron en crear una publicación para que tanto hombres como mujeres pudieran formarse y expresarse terminó sus actividades en enero de 1875, así como también terminó su amistad.

\subsection{La Patria (1871-1880) y sus redes de poder}

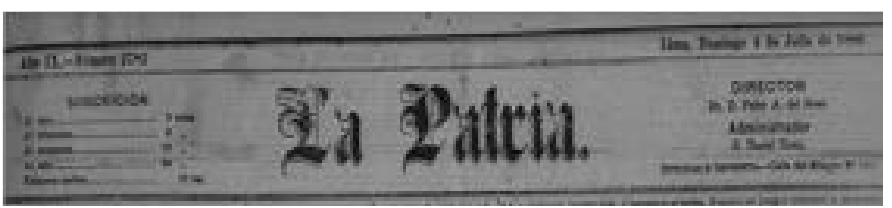

Imagen 4. Diario La Patria

La Patria fue un diario eminentemente político, combativo y en lucha permanente contra el gobierno de Pardo. Fue anticivilista y propierolista, y se atribuye que fue financiado por Dreyfus (Gargurevich 1977: 31) a quien se le relacionaba con Nicolás de Piérola desde que fue ministro del presidente José Balta.

Ser parte del diario La Patria significó apoyar su línea política. La columna la Revista de Lima del año 1880 en el marco de la guerra de Perú contra Chile, fue un soporte sólido que desplegó Carolina Freyre para el gobierno de Nicolás de Piérola ${ }^{31}$. Entre las enseñanzas cívicas a sus lectoras, en clave maternal, la república estaba a salvo, pero por el estado de

31 En diciembre de 1879, tras las batallas perdidas en la guerra contra Chile, Nicolás de Piérola asumió el mando del gobierno como jefe supremo, tras el vacío que dejó el presidente Mariano Ignacio Prado luego de su inesperado viaje. 
guerra en que se encontraba el país fue necesario apuntalar su gobierno castrado en democracia. "Sólo así se conciben las dictaduras y es sabio y es previsor y es prudentísimo en alto grado, conservar sin resistencias, sin ódios ni rencores, ese poder supremo destino hoy á recobrar el brillo y honor de nuestra bandera momentáneamente eclipsados" (La Patria. Lima, 10 de enero de 1880).

Los lazos amicales entre los Jaimes Freyre y Piérola se reforzaron con el compadrazgo establecido por el pequeño Federico Nicolás, hijo de los Jaimes Freyre. La afinidad con el líder es perceptible en el saludo que Carolina extendió por su cumpleaños y su entusiasmo por propalarlo en su columna:

El lunes la víspera de la pascua de reyes, el pueblo de Lima tuvo, ocasión de manifestar su afecto y entusiasmo por el nuevo jefe supremo don Nicolás de Piérola, con motivo de su cumpleaños. Como en mejores tiempos, la bella plaza de la capital se vió resplandeciente de luces impregnada de perfumes, llena con las armonías de la música, é inundada de una multitud bulliciosa, festiva y alegre, que vitoreaba al ilustre patricio, augurio para el Perú de bienandanza, de prosperidad y de gloria (La Patria. Lima, 10 de enero de 1880).

Los elogios también se desplegaron a propósito de los eventos organizados por su pariente espiritual el financista Dionisio Derteano. En esas reuniones se notaba la prodigalidad

224 del anfitrión con los redactores de La Patria, principales defensores de la casa Dreyfus (Holguín 1982). Los convites fueron referencia de exquisitez y muy comentados en la alta sociedad limeña; Carolina describió uno de esos agasajos de esta manera:

El viernes continúa la brillante asamblea en torno de la bien servida mesa del señor Derteano. Hombres notables por su 
talento, por su posición, su fortuna o su rango, tienen el placer de concurrir a esta reunión, sin que obste el color político, ni las divisiones de partido. Brilla allí la chispa y el buen decir luce el talento, y las producciones de la inteligencia, siempre que contribuyan al buen humor, a la expansión y a la alegría, tienen entusiasta culto. ¡Esto en mi entender se llama llenar de flores la senda de la vida! Debemos confesar que sólo el sexo masculino sabe divertirse. (Lima. La Revista de Lima, julio de 1876, citado por Holguín 1982: 220).

El ambiente festivo propiciaba acuerdos, discusiones y favores. Alrededor de Derteano se daban cita altos personajes del gobierno, de la política y la sociedad. La reunión de cada viernes fue motivo para refrescar las diferencias políticas. "Los elementos ligados al anticivilismo fueron, al parecer, los más notables, ya que La Patria se señalaba como el principal órgano periodístico de esa corriente de opinión” (Holguín 1982: 220221). De hecho, la presencia de Julio Lucas Jaimes no faltó en el entretejido de redes políticas, económicas y sociales entrelazando las influencias que se tramaban en esas reuniones.

De una de esas reuniones procede el impreso al que Carolina Freyre alude como "producciones de inteligencia". Son composiciones de "críticas caricaturescas a menudo teñidas de ironía y hasta de malevolencia contra tal o cual personaje"32. El prólogo redactado por Jaimes deja en evidencia el grado de familiaridad con el anfitrión Dionisio Derteano: "Concluyo, pues, mi labor, tan grata como mal desempeñada; y concluyo consignando un rasgo de rigurosa justicia, el cual consiste en dar al César lo que es del César, o sea a Derteano

32 Entre risas e ironías es posible que en una de esas reuniones se haya pensado en la caricatura de La Mascarada "El último día de César", que se ha referido en páginas anteriores. 
lo que es de Derteano, pues a él, a su carácter expansivo y caballeroso, se deben las dulces horas que han dado por fruto este libro [...]" (Holguín 1982: 221), refiriéndose además al costo sufragado para la publicación del breve impreso.

Otra muestra de los acuerdos surgidos de esas tertulias es la que protagonizó Nicolás de Piérola cuando intervino en la conformación de la plana de redactores de La Patria. Ricardo Palma, en una de sus cartas, le recuerda que en una reunión "[...] tocamos a la ligera la cuestión prensa y casi quedé comprometido con usted a encargarme de la redacción en jefe de La Patria” en reemplazo de Julio Lucas Jaimes quien renunció a la publicación pocos días antes (Palma 1964: 17-18) ${ }^{33}$. El acuerdo, que no llegó a materializarse por diferencias de Palma con el director del diario Pedro A. del Solar, muestra el juego de intereses entre camarillas y simpatizantes alrededor de un líder que los aglutinaba34. La letra "[...] apareció como la palanca del ascenso social, de la respetabilidad pública y de la incorporación a los centros de poder" (Rama 2002: 74); la prensa y sus redactores, entre ellos Carolina Freyre, llegaron a constituirse en esa plataforma desde la cual arreciaban contra los opositores del gobierno.

33 Pese al acuerdo, Palma rechazó la oferta por el comentario que le hizo del Solar respecto a que el cargo "iba a estar (encargado) a un caballero podrá valer mucho pero cuya reputación como escritor está todavía inédita...". En esta carta, Palma se disculpa con Piérola y le pide que lo releve "de todo compromiso para con La Patria".

34 Durante el gobierno de Balta, la "peña literaria" de Palma gozó del mecenazgo de Enrique Meiggs. A decir de Luis Alberto Sánchez, "Los escritores disfrutaron de tranquilidad material y de relativo 'confort'; pudieron escribir con libertad y editar sus obras con elegancia, trasladándose frecuentemente a Europa”. Precisamente, Palma culminó sus Tradiciones en aquel periodo (Sánchez 1972, p. 105). 


\subsubsection{La columna "Revista de Lima"}

Un sumario encabezaba la columna resumiendo los temas que vendrían más adelante; a continuación, el saludo dirigido a sus lectoras como un llamado para iniciar el monólogo amical, familiar, educativo e informativo con temas sobre la actualidad nacional e internacional, el progreso del país y reflexiones morales con un estilo personal caracterizado como "anecdotillas" (Herrera 2012) y temas políticos que pretendían, que fuesen leídos no solamente por el segmento femenino.

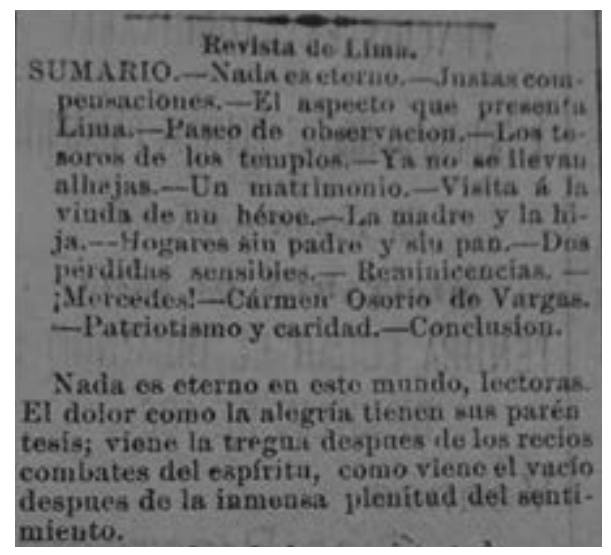

Imagen 5. Columna "Revista de Lima" del diario

La Patria (24 de julio de 1880)

Como se anotó, Carolina Freyre de Jaimes fue una escritora de reconocida aceptación no solo en el sector femenino. $L a$ Patria, a pesar de su naturaleza política, veía una oportunidad de ganar ese público, lo que se explica por la lenta pero progresiva alfabetización de las mujeres. Muchas de ellas, procuraban mantenerse informadas y qué mejor que ganarlas como asiduas lectoras sabatinas. Eso explicaría el hecho que 
el diario, desde 1871, reservase cada sábado la cuarta parte del formato para dedicarlo a este público ${ }^{35}$.

Desde que Piérola asumió la jefatura suprema, La Patria se convirtió en el órgano periodístico "oficialista" que transmitía las disposiciones gubernamentales y también opinaba favorablemente sobre las decisiones del presidente procurando persuadir a la población respecto a sus capacidades de líder. Así, los editoriales se dedicaron exclusivamente a reproducir sus actividades. Las cartas de la ciudadanía del interior del país se reprodujeron íntegramente con la intención de publicitar la simpatía y ganar la aceptación del gobernante. Los sábados, la columna de Carolina, además de sus propios temas, recordaba, algunas veces, a sus lectoras y lectores las noticias más importantes comentadas durante la semana por Julio Lucas Jaimes en el editorial. En 1880 los temas giraban en torno a asuntos gubernamentales y la guerra, y los comentarios de la escritora tomaban un cariz patriótico que buscaba sobrellevar la situación bélica adversa al país.

La última comunicación patriótica y de la columna Revista de Lima de Carolina Freyre en La Patria fue el 11 de setiembre de 1880. Una semana después, la dirección del diario emitió el siguiente comunicado en el que sin explicar los motivos y en líneas generales anunciaba el retiro de los esposos de la redacción:

Satisfaciendo un deseo del señor Jaimes, redactor principal de este diario durante diez años, creemos conveniente ma-

35 La Patria se presentaba en una hoja suelta de 48 x $67 \mathrm{~cm}$ de siete columnas. Por lo general, la "Revista de Lima" ocupaba entre dos a cuatro en la plana posterior. La "Revista de Lima" fue permanente, pero con breves interrupciones como su traslado a El Álbum. 
nifestar por hoy, que por convenir á sus intereses se retira de la redacción que ha desempeñado satisfactoriamente, debiéndole "La Patria" en gran parte el crédito de que hoy disfruta. La señora Carolina Freyre de Jaimes envía también su despedida [en "La Patria"] á sus lectoras con quienes en breve reanudarán sus relaciones literarias (La Patria. Lima, 18 de setiembre de 1880).

Por la guerra, las posiciones individuales se modificaron. Julio Lucas se enroló al ejército aliado con el grado de coronel (Valda 1972: 10), probablemente desde el momento de su renuncia al diario. En cuanto a Carolina, madre de pequeños niños, el último de apenas un año y tres meses, permaneció junto a ellos por los temores propios de la guerra. Lamentablemente, la comunicación de la escritora con sus lectoras no se reanudó. La voz de la columna la Revista de Lima, testigo de la vida cotidiana limeña por casi una década, se apagó.

\subsubsection{El cese de La Patria}

Meses antes de la ocupación de Lima por las tropas chilenas, su flota bloqueó los puertos del litoral con el fin de limitar el abastecimiento de subsistencias y el suministro de armas. Como efecto de esta táctica de guerra, muchas actividades dejaron de realizarse o disminuyeron su productividad, como la impresión de periódicos y revistas por la carencia de papel y tinta, implementos básicos de la impresión que eran importados y se hicieron cada vez más escasos. La voluntad de continuar informando obligó a El Nacional, La Patria y El Comercio a concertar un precio único para subsistir. En su momento, La Patria explicó a sus lectores el acuerdo de los tres directores de los principales periódicos:

Agotados ya los sacrificios de capital, de economía y de trabajo para sostener los referidos periódicos, sin aumentar el 
precio de la suscripción ó de los números sueltos, es absolutamente imposible continuar publicándolos, si sus abonados á quienes sirven no los auxilian hasta cubrir siquiera en parte, el enorme déficit que les ha producido y les produce el excesivo costo del papel, carbón, tinta y demás útiles de imprenta, hasta que mejoren las condiciones financieras del país y permitan volver á los precios antiguos ó hacer las rebajas proporcionales (La Patria. Lima, 3 de setiembre de 1880).

Los precios se elevaron al cien por ciento respecto al anterior. A la pregunta, ¿hasta cuándo se emitió La Patria? Probablemente, hasta la primera semana de enero de 1881, pocos días antes que Lima fuese invadida por los chilenos. La Biblioteca Nacional conserva la edición del 18 de diciembre, pese a su condición, aún se puede apreciar la fecha.

La Patria no dejó de funcionar por la prohibición, sino por el saqueo. El taller-imprenta del diario desapareció antes de que se diese la orden. La infraestructura del local permaneció en su lugar dada la imposibilidad de embarcarla hacia Chile. Patricio Lynch consignó en su Memoria que ante el pedido de su gobierno del envío de las máquinas y equipos de las imprentas limeñas, la que correspondía a La Patria no pudo hacerse, porque su ejército adelantó el saqueo. Explícitamente, indica que "La imprenta por donde se publicaba el diario 'La Patria' órgano oficial del Dictador, había desaparecido por completo, i remitida á Chile, se hallaba fuera de mi acción, por lo cual me fué imposible tomar directamente medidas para recuperar i castigar á los autores de la sustracción” (1882: 75-76).

Basadre, cuando se ocupa del ambiente de Lima invadida, refiere que los nombres de la prensa representativa de la capital se reasignaron a los medios informativos que los chile- 
nos establecieron en Lima y en el Callao pretendiendo crear un clima de normal desarrollo de actividades. Es inexacto afirmar que La Patria peruana siguió operando hasta 1882 (Barrenechea 1970: 35), ya que sin imprenta no pudo existir. Los periódicos y revistas que en su momento albergaron a los escritores, ya no existían; hacia 1880, uno a uno fueron cerrando ya sea por falta de insumos, saqueo del local o porque quienes los dirigían o manejaban los equipos se enlistaron en los batallones ${ }^{36}$, murieron en batalla, cayeron presos y fueron trasladados a Chile o salieron del país a la espera de que la guerra terminase para regresar.

\section{Estaciones previas hacia el último destino (1881-1916)}

Por lo general, la responsabilidad de las mujeres en las guerras se incrementa, pues ellas deben sacar adelante a sus ancianos y niños, proveerles alimento y brindarles cobijo y seguridad. En febrero de 1881, con las tropas chilenas asentadas en la capital, Carolina Freyre se trasladó con sus hijos a su natal Tacna ${ }^{37}$, también ocupada militarmente, para permanecer con su familia. Su esposo, el coronel Julio Lucas Jaimes fue detenido en Lima el primero de febrero de 1881 y al día

36 Mediante bando se dispuso el "[...] enlistamiento en masa de todos los peruanos varones existentes en la capital, que no hayan cumplido 60 años, ni sean menores de 16..." en diez divisiones. Cada ciudadano debió inscribirse en su gremio ocupacional "no pudiendo hacerlo en ningún otro”. firmado por el Prefecto del Departamento de Lima coronel Juan Martín Echenique. La Patria, 9 de julio de 1880.

37 En la solicitud que presentó la señora Natividad Moreyra viuda de Frisancho, con fecha 7 de febrero de 1882, para sentar la partida de bautizo del niño Federico Nicolás, señala que Carolina Freyre, la madre, se encontraba en Tacna. 
siguiente fue embarcado al depósito de prisioneros de guerra de San Bernardo (Palma 1964: 27).

Palma, en una de las misivas que remitió a Nicolás de Piérola, le comentó que el azote a los peruanos, especialmente a los personajes políticos, se convirtió en una práctica común de los chilenos. "Hubo en el primer momento el propósito de azotar a Jaimes en la plaza de Lima [...]” (Palma 1964: 64). La violencia y la muerte rondaron de cerca a Jaimes. En Chile se libró de ser condenado a muerte por la intervención de las damas de la villa de San Bernardo, quienes enteradas de su historial literario intercedieron por su vida ante las autoridades chilenas (Gambetta 1988: 9). A pesar del vínculo espiritual y político con el dictador Nicolás de Piérola, Jaimes salvó de morir.

\subsection{Sucre y $E l$ Álbum ${ }^{38}$. Tacna y La Bohema Tacneña}

Se desconoce, exactamente, hasta cuando permaneció Jaimes como prisionero de guerra. No obstante, hay noticias de la familia Jaimes-Freyre en La Paz en 1882, donde publicaron Las Verdades; luego se trasladaron a Sucre para dirigir La Industria. Carolina se reposicionó como escritora y en mayo de 1889 consolidó su proyecto de dirigir la primera publicación femenina en Bolivia, esta vez en Sucre: El Álbum. Publicación Semanal, Literaria, de Modas y de Costumbres dedicada a las señoras.

38 Imagen $\mathrm{N}^{\circ}$ 5. El Álbum de Sucre. Nuestro agradecimiento al doctor Alberto Varillas Montenegro por la copia del ejemplar n. ${ }^{\circ} 1$ cedido a la autora de este artículo. 


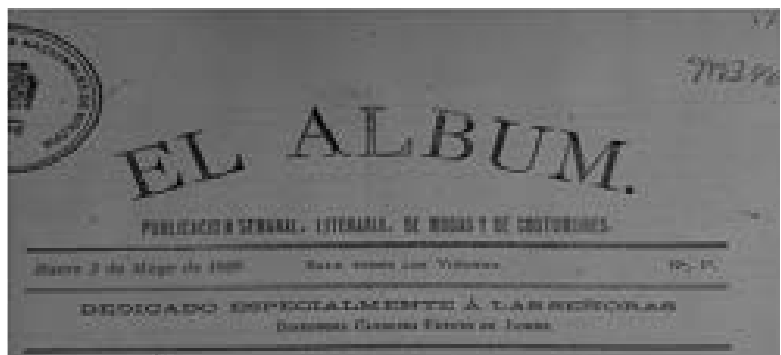

Imagen 6. El Álbum de Sucre

Los viajes de Carolina a Tacna fueron frecuentes. El deseo de mantener vivos los valores patrios en la tierra invadida por los chilenos la inspiró a fundar La Bohemia Tacneña en 1886, junto a otros intelectuales tacneños y ariqueños. En 1897, la escritora Amalia Puga publicó un grabado con los integrantes en la revista Letras, vocero oficial de La Bohemia Tacneña; así lo describe:

Hay una cabecera y la ocupa una mujer superior: Carolina Freyre de Jaimes, poetisa tierna y de elevada inspiración, los acordes de cuyo laúd han arrullado el nacimiento de la moderna literatura tacneña. Y hay un centro y lo ocupa, con sobrados títulos Modesto Molina el cantor de Mercedes, el Pontífice. A la diestra de Carolina Freyre de Jaimes está su talentoso hijo Ricardo Jaimes Freyre, poeta de raza, compañero de labor un tiempo- y de exquisitos ideales parnasianos -siempre- de Rubén Darío (citado por Pango Vildoso 1979: 5).

Más tarde, Carolina propuso nombrar a Palma como Patriarca de las letras peruanas. Su feliz aceptación, de fecha 25 de diciembre de 1891, desdice supuestas desavenencias entre ambos escritores, probablemente inducidos por la ojeriza engendrada por Juana Manuela Gorriti hacia los Jaimes. 
Al Pontifice Romano

$Y$ demás gente pequeña,

Grande o de porte mediano

De la Bohemia Tacneña.

Saludy bendición en Jesucristo

Que fue de Galilea en la Bohemia,

Un bohemio de marca.

Yo, a quién nombráis Patriarca,

Honra que acepto y con la cual me invisto

Porque hartas horas de fatiga premia,
Desde Lima en que vivo,

Desempolvando el Nacional Archivo

$Y$ matando polilla,

A granel, con escoba y escobilla,

Os acuso recibo,

En serio más que en broma,

Del galante diploma

Con que jovial la juventud tacneña

En su falangue enrólame risueña

$[\ldots]$

(Citado por Gonzales 1952: 5354).

Con la designación de Jaimes, por el presidente boliviano Aniceto Arce como embajador de Bolivia ante la corte de Don Pedro II, la familia partió a Brasil, pero en el tránsito permaneció en compás de espera en Buenos Aires; allí tomó conocimiento del levantamiento de Deodoro da Fonseca contra el trono imperial (Iglesias 1992: 228-237). Su establecimiento como presidente, en noviembre de 1889 de la nueva república, hizo perder la expectativa diplomática de Jaimes. Con esta contingencia, la familia decidió fijar su residencia en Buenos Aires, donde muchos connacionales y conocidos se habían afincado, entre ellos, Juana Manuela Gorriti.

En comunicación con Palma, del 6 de febrero de 1890, Gorriti le comentó despectivamente: "Aquí está Jaimes hecho todo un Ministro Plenipotenciario de Bolivia cerca del flamante gobierno republicano del Brasil. Dice que aguarda para pasar a su destino... pero yo creo que ha llegado, [y] aquí se ha encontrado en seco y aguarda manis [dinero] de Bolivia ¡Ay! ¡Algo escaso!” (Citado por Batticuore 2004: 87). 
Jaimes fue contratado como redactor en La Nación (Núñez 1979: XXXI) y pese a su animadversión, Gorriti se mantuvo atenta a sus actividades. El 6 de diciembre de 1890 sostuvo:

Han reído mucho de Jaimes, que ha pretendido imitarlo, retocando en La Nación algunas de esas tradiciones potosinas que publicaba en La Patria de Lima. Aquí está con su familia, dicen que en muy mal estado de finanzas. Venía encargado de Negocios de Bolivia a Brasil; llegó aquí -dicen también- sin dinero, y por tanto, no pudo seguir viaje a su destino, y aquí se ha quedado, no sé si por aquello o por la caída del Imperio. Qué mala figura hacen éstos que a toda costa quieren figurar (Batticuore 2004: 104).

La animosidad de Gorriti se refleja en el tono burlesco cuando se refiere a los Jaimes. El 9 de setiembre de 1890 señaló: "Y a propósito Jaimes está aquí plagiando a U. desde el estilo, desde el lenguaje, hasta la fisonomía de las Tradiciones con un descaro y al mismo tiempo con una yuyonería [sic] que hace reír. Aquí llegó lleno de ínfulas de Ministro cerca de una corte imperial. Gastó adelantos que se le hicieron. Y ahora, aunque va a representar a su país en una república democrática, se ha quedado en seco y no puede pasar adelante" (Batticuore 2004: 98). Su desafecto la animaría a crear hostilidad entre Jaimes y el escritor de las Tradiciones; lo acusó de plagio por adoptar el estilo de Palma en los cuentos costumbristas que escribía para algunos diarios publicados también en La villa imperial de Potosí (Jaimes 1969). El mismo estilo que tomó su "ahijada" Clorinda Matto de Turner cuando escribió Tradiciones cusqueñas ${ }^{39}$ en 1886.

39 Clorinda Matto de Turner dedicó su obra "A la ilustrada escritora argentina sra Juana Manuela Gorriti prenda de cariño y gratitud". 


\subsection{Buenos Aires: Último destino. La feminista conser- vadora}

A principios del siglo XX, Carolina Freyre se instaló en Buenos Aires, trabajó para diversas revistas en Argentina, colaboró en La Ondina de Plata y también en La Nación, donde Jaimes trabajaba como redactor; dirigió la revista La columna del hogar y fundó con Carlota Garrido de la Peña La Revista Argentina (1902-1905). En San Miguel de Tucumán colaboró con El Orden y en Salta, con Nueva Época y Güemes (Sosa 1986).

Simultáneamente, fue miembro activo del Consejo Nacional de Mujeres. En ese tiempo, emergía una nueva imagen de lo femenino vinculada a los cambios socioeconómicos y el acceso de la mujer al mercado laboral. Frente a la irrupción del discurso progresista de las feministas, Carolina Freyre aceptó las innovaciones de la modernidad, pero defendió la conservación del tradicional rol femenino en la sociedad. Esta posición se puede apreciar en su discurso que pronunció en el marco de las celebraciones del centenario de la Revolución de mayo en 1910 en el Primer Congreso Patriótico Femenino de Señoras de la América del Sud organizado por el Consejo Nacional de Mujeres. En su presentación sostuvo:

[E]l Consejo Nacional de Mujeres, primera sociedad feminista de esta tierra amada, no caben las escenas de caricatura grotesca de las sufragistas exaltadas, pertenecientes al feminismo callejero, que camina perorando en Club al aire libre y armando camorra en los mitins populares. Estas son las manchas feas, los lunares postizos del gran cuadro... Y nuestro feminismo es dulce y tranquilo; reivindica sólo el derecho de pensar, de escribir, de trabajar, de ganar honradamente la vida; da lo que las flores al que las cultiva; perfumes y lozanía ...En este orden el socialismo nada tiene 
que ver con nuestro feminismo... Pero este ideal [socialista] más o menos claro, más o menos confuso llegará á ser quizá una revolución social posible, pero todavía lejana, es por el momento incompatible con las ideas del progreso de la mujer, con las aspiraciones de elevada ambición del feminismo actual. Por eso no lo analizamos (Reiter 2002) ${ }^{40}$.

Como miembro del Consejo Nacional de Mujeres, visitó Lima para dictar una serie de conferencias referidas a la actividad social de la mujer sudamericana (García 1925: 23-25). En el ocaso de su vida, la diabetes afectó su visión; trató de superar las consecuencias de la enfermedad sometiéndose a una intervención quirúrgica cuya cicatrización fue larga y dolorosa, y la pérdida de la visión, inminente. En una carta que dirigió a uno de sus hijos confesó: “[...] casi no veo, escribo a tientas, no lo haría si no fuese por la costumbre que tengo de escribir" (Valda: 1972: 24-25).

La escritora tacneña Carolina Freyre de Jaimes falleció en Buenos Aires el 29 de mayo de 1916 a los 72 años de vida, dos años después de la muerte de su esposo, el impetuoso periodista boliviano Julio Lucas Jaimes.

\section{Conclusiones}

En la segunda mitad del siglo XIX, el peso de la herencia colonial continuó restringiendo el desenvolvimiento y desarrollo de la mujer en el espacio público, pese a ello, algunas sobresalieron tras mucho esfuerzo. La escritora tacneña Carolina Freyre de Jaimes logró consolidarse por su talento y

40 Citado por Bárbara Reiter. 2002, pp. 259-261 Consulta: 15 de enero de 2015. En línea: < http://www.cedinci.org/jornadas/2/M3.pdf> 
construyó su espacio con el respaldo e impulso de su esposo, el político y escritor boliviano Julio Lucas Jaimes. Este formó, junto a hombres fuertes de la política, la cultura y las finanzas, la oposición al civilismo bajo el ala de Nicolás de Piérola. En este marco, los esposos Jaimes-Freyre fortalecieron sus lazos y vínculos en el entramado del poder nombrando como padrino del pequeño Federico Nicolás a Nicolás de Piérola y como testigo a Dionisio Derteano.

En 1871, a poco de establecerse en la capital, Carolina Freyre de Jaimes ya escribía para algunas publicaciones en las que su nombre era conocido por sus artículos enviados desde Tacna. En ese mismo año, Julio Lucas comenzó a trabajar en el diario La Patria y unos meses después se sumó a la plana periodística Carolina Freyre de Jaimes con su columna sabatina "Revista de Lima" dirigida al segmento femenino. Esto significó su alineación pública en la oposición política al civilismo. Así lo hace ver en 1880, cuando se dirigió a sus lectoras apoyando la asunción al poder de Nicolás de Piérola como jefe supremo y defendiendo sus decisiones en el contexto de la guerra contra Chile. Con la "Revista de Lima", en ese año, por los temores propios de la guerra, canalizó los miedos y aflicciones de la población hacia actividades solidarias con los connacionales y se convirtió en fuerza de choque contra las críticas al gobierno pierolista provenientes del civilismo y 238 de la prensa chilena.

El conocimiento y experiencia adquirida en la imprenta familiar de Tacna la habría inspirado a embarcarse en su propio proyecto periodístico El Álbum (1874-1875), el cual hizo realidad con el apoyo de La Patria logrando materializarlo desde su imprenta; al mismo tiempo, se configuró en la historia del periodismo nacional como la primera publicación 
dirigida por mujeres. Efectivamente, Carolina Freyre junto a Juana Manuela Gorriti llevaron adelante la publicación como codirectoras, pero el acompañamiento duró menos de cuatro meses cuando Gorriti terminó la sociedad con una escueta nota en la que anunciaba su alejamiento de El Álbum. Los motivos se desconocen; sin embargo, no se descarta que la vehemencia periodística de Julio Lucas Jaimes obró como percutor cuando difundió en sus Tradiciones potosinas el chisme de alcoba que tuvo como protagonistas a Gorriti, Belzú y Ballivián, y publicó la representación gráfica "El último día de César", lo que coincidió con el atentado contra la vida de Pardo con cuya persona y partido simpatizaba. Estos y otros hechos terminarían por distanciar a las otrora socias. Con el tiempo, Gorriti anidó sentimientos de rencor y animadversión hacia los Jaimes Freyre que la acompañaron hasta el final de sus días. Estos motivos explican la ausencia de Carolina Freyre de Jaimes en las populares veladas literarias de Juana Manuela Gorriti.

Respecto a su "Revista de Lima", su última edición fue el 11 de setiembre de 1880, no antes ni después de esta fecha. Su vigencia la convierten en una de las más longevas en ese siglo respecto al quehacer periodístico femenino. Es importante también señalar la fecha de cierre de La Patria por el vínculo profesional con la escritora. Este diario, anticivilista y propierolista, de incansable vida política fue acallada con el saqueo de la invasión chilena. Es inexacta la información que sostiene que La Patria continuó vigente hasta 1882.

Por otra parte, los datos que proporciona José Domingo Cortés en su Parnaso Peruano carecen de veracidad; lamentablemente, la información se repite y difunde sin detenerse en 
las ambigüedades que presenta ${ }^{41}$. La confrontación de fuentes primarias y secundarias dejó en evidencia que los trabajos de Cortés, en particular, fueron preparados en función de la ganancia económica que le redituarían los personajes presentados, lo que habla de la popularidad que gozaban los personajes de las letras de su tiempo. Precisamos que la niña Carolina Freyre Arias creció en un hogar ilustrado y que su educación se vio favorecida por el esmero que pusieron sus padres en estimular su talento; para ello, habría contado con maestros privados que le enseñaron a desarrollar sus habilidades para las bellas letras y otras áreas del saber. La niña no asistió a las Educandas entre los tres o cuatro años de edad; y en su adolescencia se colocó a la vanguardia de sus contemporáneas, por lo que pudo haber sido nombrada asistente de maestra, difícilmente como maestra de aritmética.

La investigación en el Archivo Arzobispal de Lima permitió conocer a un descendiente más del matrimonio JaimesFreyre. Los datos de los padres en la ficha de inscripción del niño Carlos Alberto, de nueves meses y siete días, en el momento del bautizo, no dejan lugar a dudas; probablemente falleció a muy temprana edad. Julio y Carolina tuvieron siete hijos. Esta información inédita enriquece la reconstrucción biográfica que ofrecemos.

240 En todo ese tiempo, la escritora tacneña Carolina Freyre de Jaimes hizo política a pesar de estar fuera de lo convencionalmente aceptado para una mujer. Apoyó la línea política del diario La Patria, apuntaló el gobierno de Nicolás de Piérola

41 Elvira García y García tomó la información del Parnaso Peruano para su Mujerperuana a través de los siglos (1924-1925, pp. 23-25); esta referencia ha sido registrada en algunos trabajos que se ocupan de la escritora tacneña. 
y lo patrocinó con su discurso ante la lectoría de su columna "Revista de Lima". Vigorizó sus redes de poder junto a su esposo Julio Lucas Jaimes, con Nicolás de Piérola y Dionisio Derteano entre otros líderes notables. Carolina Freyre de Jaimes fue una mujer fuera de lo convencional. Madre de siete niños, esposa del vehemente político y periodista Julio Lucas Jaimes, escritora, poetisa, dramaturga, política, emprendedora, feminista, patriota y nacionalista. Su historia comienza a escribirse.

Carolina Freyre de Jaimes falleció el 29 de mayo de 1916. Sea esta aproximación biográfica un homenaje en el centenario de su muerte.

Recibido: 12 de octubre de 2016

Aprobado: 10 de enero de 2017

\section{Bibliografía}

\section{Publicaciones periódicas}

El Comercio

El Álbum

El Correo del Perú

La Patria

El Nacional

La Opinión Nacional

\section{Fuentes primarias}

Archivo Arzobispal de Lima

Congreso de la República del Perú (leyes) 
COPELLO, Juan

$1870 \quad$ Nuevos estudios para determinar las causas, la naturaleza y el tratamiento de la fiebre amarilla. Lima: En la Imprenta de "El Nacional"

CORTÉS, José Domingo

1875 Poetisas americanas. Ramillete poético del bello sexo hispanoamericano. París: Librería de A. Bouret e hijo

1871 Parnaso peruano. Valparaíso: Imprenta Albión de Cox y Taylor

FELIPE III

1805-1929 Novísima Recopilación de las leyes de España divididos en XII Libros. Madrid: Sachs

GARCÍA Y GARCÍA, Elvira

1924-1925 La mujerperuana a través de los siglos. Lima: Impr. Americana

GORRITI, Juana Manuela

1892 Veladas literarias de Lima. Buenos Aires: Imprenta Europea.

JAIMES, Julio Lucas

1969 La villa imperial de Potosí. Buenos Aires: Eudeba

LARRABURE Y UNANUE, Eugenio

1934-1936 Manuscritos y publicaciones: bistoria y arqueología. Lima: Impr. Americana.

LYNCH, Patricio

1882 Memoria que el contra-almirante D. Patricio Lynch jeneral en jefe del ejército de operaciones en norte del Perú presenta al supremo gobierno de Chile. Lima: Imp. Calle Húsares de Junín. 
MATTO DE TURNER, Clorinda

1886 Tradiciones Curqueñas. Lima: Imp. de Torres Aguirre, Mercaderes 150

PALMA, Ricardo

1964 Cartas a Piérola: sobre la ocupación chilena de Lima. Lima: Editorial Milla Batres.

PARDO, Manuel

1876 Reglamento General de Instrucción Pública. Lima: Imprenta del Estado.

QUIRÓS, Mariano Santos de y Juan Crisóstomo NIETO (compilador)

1831-1853 Colección de leyes, decretos y órdenes publicadas en el Perú desde su independencia. Tomo I. Lima: Imp. José Masías; Huaraz: Imp. De la Colección.

SORS, Sebastián

1869 Memoria bistórica de la fiebre amarilla que sufrió la ciudad de Tacna en el presente año de 1869. Tacna: Imprenta de "El Porvenir".

SUÁREZ, José Bernardo

1872 Rasgos biográficos de mujeres célebres de América. Escritos traducidos y estractados para el uso de las jóvenes. París: C. Bouret.

\section{Fuentes secundarias}

BASADRE GROHMANN, Jorge

2009 Infancia en Tacna. Lima: Peisa.

1983 Historia de la República del Perú 1822-1933. Lima: Editorial Universitaria.

BATTICUORE, Graciela

2005 La mujer romántica. Lectoras, autoras y escritoras. 
$2004 \quad J u a n a$ Manuela Gorriti. Cincuenta y tres cartas inéditas a Palma. Fragmentos de lo intimo. Lima: USMP.

1999 El taller de la escritora. Veladas literarias de Juana Manuela Gorriti. Rosario: Beatriz Viterbo Editora.

BERG, Mary G.

1997 "Juana Manuela Gorriti: narradora de su época”. En Las desobedientes: Mujeres de nuestra América. Bogotá: Panamericana Editorial.

CASTAÑEDA VIELAKAMEN Esther y Elizabeth TOGUCHI KAYO

2000 "Carolina Freire de Jaimes: La fundación del discurso crítico femenino en el Perú. Mujer, cultura y sociedad en América Latina. Lima: Fondo Editorial de UNMSM, pp. 41-50.

CHAMORRO UGARTE, Guillermo

1977 "Centenario de un drama". En El Comercio. 21 de mayo de 1977.

DENEGRI, Francesca

1996 El abanico y la cigarrera. La primera generación de mijeres ilustradas en el Perú. Lima: Ediciones Flora Tristán, IEP.

ESCALA ARANÍBAR, María del Carmen

2015 El ángel del hogary el ángel de la guerra. El discurso patriótico maternal de Carolina Freyre de Jaimes y su afirmación nacionalista desde el diario La Patria ad portas de la Ocupación de Lima 1844-1880. Tesis de licenciatura en Historia. Lima: Pontificia Universidad Católica del Perú, Facultad de Letras y Ciencias Humanas.

FELIÚ CRUZ, Guillermo

1933 En torno de Ricardo Palma. Santiago de Chile: Prensas de la Universidad de Chile. 
GAMBETTA, Freddy

2001 Nueva crónica del tiempo viejo. Historia de Tacna. 18661924. Tacna: Editorial Industria Gráfica Regentus.

1988

Ricardo Jaimes. Tacneño continental. Tacna: Editorial Cal\&Canto.

GARGUREVICH REGAL, Juan

1977 Introducción a la historia de los medios de comunicación en el Perú. Lima: Horizonte.

GLAVE, Luis Miguel

1995 "Letras de mujer: Juana Manuela Gorriti y la imaginación nacional andina, siglo XIX". Revista de la Dirección de Estudios Históricos del Instituto Nacional de Antropología e Historia (INAH). $\mathrm{N}^{\circ}$ 34. Consulta: 24 de diciembre de 2014.

hppt://www.estudioshistoricos, inah.gob.mx/revista Historia/wp-content/uplods/historias_34_ 119_138.pdf>

GONZÁLEZ MARÍN, Carlos Alberto

1970 La escuela peruana en Tacna (1793-1907). Lima: [s/n].

1965-1966 "Breve historia del periodismo peruano en Tacna". Boletín Bibliográfico: UNMSM, vol. 38-39.

1952 Antología histórica de Tacna. Lima: Imprenta Leoncio Prado.

HALPERÍN DONGHI, Tulio

1985 Reforma y disolución de los imperios ibéricos, 17501850. Madrid: Alianza Editorial.

https://doi.org/10.2307/2515081

HERRERA LIENDO, Patricia

2012 La construcción discursiva de la mujer limeña desde la perspectiva de Carolina Freyre de Jaimes en la "Revista de Lima" de 1872 a 1874. Tesis de licenciatura en Litera- 
tura. Facultad de Letras y Ciencias Humanas. Lima: UNMSM.

HOLGUÍN CALLO, Oswaldo

1982

"Política y literatura en un impreso limeño de 1876". Boletín del Instituto de Riva Agüero $\mathrm{N}^{\circ} 12$, pp. 217-250.

IGLESIAS, Francisco

1992 Historia política de Brasil. Madrid: Fundación Mapfre.

MIRO-QUESADA LAOS, Carlos

1957 Carlos. Historia del periodismo peruano. Lima: Librería Internacional del Perú.

NÚÑEZ, Estuardo (compilador)

1979 Tradiciones hispanoamericanas. Caracas: Biblioteca Ayacucho.

PAREDES, Elsa

1965 Diccionario biográfico de la mujer boliviana. La Paz: Ediciones Isla.

PANGO VILDOSO, Grover

1979 Altas letras. Tres escritores en cautiverio. Tacna: INC.

PORRAS BARRENECHEA, Raúl

$1970 \quad$ Historia del periodismo en el Perú. Miraflores: Instituto Raúl Porras Barrenechea.

2462002 La ciudad letrada. Hanover, NH: Ediciones del Norte.

ROCHA, Omar

2014 La Aurora Literaria. "Reseña de un álbum, folletín, revista, publicada en Sucre a mediados del siglo XIX". Consulta: 20 de abril de 2015.

$<$ http: / / letrasietebolivia.blogspot. com/2014_07_01_archive.html> 
2014 “El Álbum”. Consulta: 17 de enero de 2015. <http:/ / letrasietebolivia.blogspot.pe/2014/07/cafetin-con-gramofono.html>

REITER, Bárbara

2002 "Feminismo socialista a inicios del siglo XX". II Jornadas de Historia de las Irquierdas. Buenos Aires: Centro de Documentación e Investigación de la Cultura de Izquierdas en Argentina. En línea: $<$ http://www.cedinci.org/jornadas/2/M3.pdf>

SALAS GUERRERO, César

2009-2010 "Colaboradores y corresponsales del semanario literario El Álbum (1871-1874)". Boletín del Instituto Riva Agüero $\mathrm{N}^{\circ} 35$, pp. 129-170.

SÁNCHEZ, Luis Alberto

1972 Introducción crítica a la literatura peruana. Lima: P.L. Villanueva.

SOSA DE NEWTON, Lily

2003 "Las periodistas". Cuadernos hispanoamericanos. Escritoras argentinas del siglo XIX. Salamanca: Gráficas Varona.

SOUZA, Mauricio

2005 Ricardo Jaimes Freyre. Obra poética y narrativa. La Paz: Plural Ed.

TAURO DEL PINO, Alberto

$2001 \quad$ Enciclopedia ilustrada del Perú. Lima: El Comercio.

1993 Catálogo de seudónimos peruanos. Lima: Ariel, Comunicaciones para la Cultura.

VALDA DE JAIMES FREYRE, María Luisa

1972

Un hombre fui. Biografía anecdótica de Raúl Jaimes Freyre. La Paz: Universo. 
Carolina Freyre de Jaimes, a un siglo de su muerte

VARILLAS MONTENEGRO, Alberto

1992 La literatura peruana del siglo XIX. Periodificación y caracterización. Lima: Fondo Editorial PUCP.

VÁSQUEZ MACHICADO, Humberto

1963 Manual de historia de Bolivia. La Paz: Gisbert y Cía. 